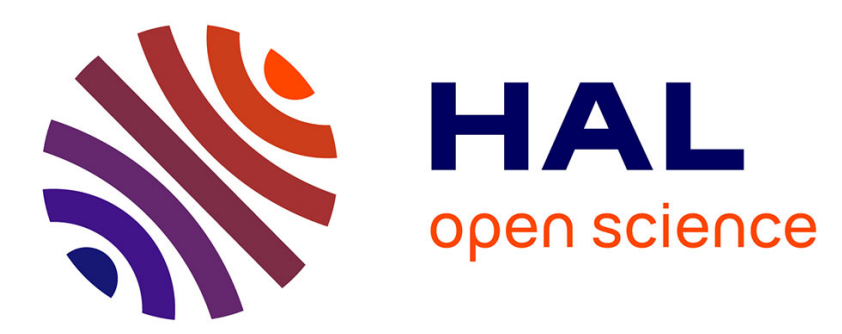

\title{
On strain and damage interactions during tearing: 3D in situ measurements and simulations for a ductile alloy (AA2139-T3)
}

Thilo F. Morgeneyer, Thibault F Taillandier-Thomas, Ante F Buljac, Lukas F Helfen, François Hild

\section{To cite this version:}

Thilo F. Morgeneyer, Thibault F Taillandier-Thomas, Ante F Buljac, Lukas F Helfen, François Hild. On strain and damage interactions during tearing: 3D in situ measurements and simulations for a ductile alloy (AA2139-T3). Journal of the Mechanics and Physics of Solids, 2016, 96, pp.550-571. 10.1016/j.jmps.2016.07.012 . hal-01383922

\section{HAL Id: hal-01383922 \\ https://hal.science/hal-01383922}

Submitted on 19 Oct 2016

HAL is a multi-disciplinary open access archive for the deposit and dissemination of scientific research documents, whether they are published or not. The documents may come from teaching and research institutions in France or abroad, or from public or private research centers.
L'archive ouverte pluridisciplinaire $\mathbf{H A L}$, est destinée au dépôt et à la diffusion de documents scientifiques de niveau recherche, publiés ou non, émanant des établissements d'enseignement et de recherche français ou étrangers, des laboratoires publics ou privés. 


\title{
On strain and damage interactions during tearing: 3D in situ measurements and simulations for a ductile alloy (AA2139-T3)
}

\author{
Thilo F. Morgeneyer ${ }^{\mathrm{a}, *}$, Thibault Taillandier-Thomas ${ }^{\mathrm{a}, \mathrm{b}}$, Ante Buljac ${ }^{\mathrm{a}, \mathrm{b}}$, Lukas \\ Helfen $^{c, d}$, François Hild ${ }^{\mathrm{b}}$ \\ ${ }^{a}$ MINES ParisTech, PSL Research University, Centre des matériaux, CNRS UMR 7633, \\ BP 87, F-91003 Evry, France \\ ${ }^{b}$ LMT-Cachan, ENS Cachan/CNRS/Université Paris-Saclay, 61 avenue du Président \\ Wilson, F-94235 Cachan Cedex, France \\ ${ }^{c}$ ANKA/Institute for Photon Science and Synchrotron Radiation, Karlsruhe Institute of \\ Technology (KIT), D-76131 Karlsruhe, Germany \\ ${ }^{d}$ European Synchrotron Radiation Facility (ESRF), BP 220, F-38043 Grenoble cedex, \\ France
}

\begin{abstract}
Strain and damage interactions during tearing of a ductile Al-alloy with high work hardening are assessed in situ and in 3D combining two recently developed experimental techniques, namely, synchrotron laminography and digital volume correlation. Digital volume correlation consists of registering 3D laminography images. Via simultaneous assessments of 3D strain and damage at a distance of 1-mm ahead of a notch root of a thin Compact Tension-like specimen, it is found that parallel crossing slant strained bands are active from the beginning of loading in a region where the crack will be slanted. These bands have an intermittent activity but are stable in space. Even at late stages of deformation strained bands can stop their activity highlighting the importance of plasticity on the failure process rather than damage softening. One void is followed over the loading history and seen to grow and orient along the slant strained band at very late stages of deformation. Void growth and strain are quantified. Gurson-Tvergaard-Needleman-type simulations using damage nucleation for shear, which is based on the Lode parameter, are performed and capture
\end{abstract}

\footnotetext{
*Corresponding author, thilo.morgeneyer@ensmp.fr
} 
slant fracture but not the initial strain fields and in particular the experimentally found slant bands. The band formation and strain distribution inside and outside the bands are discussed further using plane strain simulations accounting for plastic material heterogeneity in soft zones.

Keywords: A. Fracture mechanisms, A. Voids and inclusions, B. Metallic material, C. Finite elements, C. Mechanical testing

\section{Introduction}

The understanding and prediction of strain and damage interactions in ductile alloys remain a challenging topic due to the development of novel alloys and joining techniques, e.g., for transport applications [1, 2]. This understanding

5 is important for micromechanics-based development of new materials and the assessment of structural integrity.

The prediction of failure at various stress states still remains a challenge 3 . In particular, strain localization phenomena are important issues as they may reduce the toughness of structures [4. Their prediction is difficult as the roles of plasticity and damage softening on localization need to be clarified [5]. Such strain localization phenomena in metals have been studied theoretically by Needleman and Tvergaard [ [6] who found that they are favored by material behaviors that form a sharp vertex on the yield surface, by material damage and by heating due to plastic deformation leading to thermal softening at high strain rates. The effect of softening in bands due to strain rate sensitivity has also been investigated [7. Huang and Hutchinson assessed numerically the effect of voids and their distribution on strain localization in a band. Fleck et al. [8] analyzed theoretically the effect of nucleation and growth of voids in a shear band and showed that damage softening favors localization.

Another poorly understood phenomenon linked to localization is slant fracture during ductile tearing [9]. Slant fracture is hard to reproduce numerically [10]. This could be linked to numerical problems due to mesh dependence of local models [11]. Regularized models may overcome this issue but the reg- 
ularization length then needs to be identified in an appropriate way. Slant fracture has successfully been simulated using shear void nucleation based on the Lode parameter [12 that actually resembles the shear modification of the Gurson model [13. In Ref. [14] it has been shown via a computational cell simulation that the dissipated energy reaches a minimum when the crack is slanted. Experimentally, slant fracture is widely observed in thin walled structures [15] so and can also lead to flip-flopping phenomena [16, 17, that are neither understood nor reproduced numerically.

Shear banding has also been attributed to Portevin-Le-Chatelier effect that leads to equally spaced rough bands on the surface of a Kahn tear test specimen made of Al-Li alloy [18. In Ref. [19] the Coulomb fracture model and the 35 Portevin-Le-Chatelier (PLC) model or dynamic strain aging (DSA) are formulated at the slip system scale and slant fracture could be reproduced.

In ductile damage modeling, where nucleation, growth and coalescence of voids is generally taken into account, efforts have been made to account for void shape effects. In particular, the changes of ellipsoidal voids have been accounted for in homogenization models [20. It has been shown numerically that void reorientation can increase the susceptibility of the material to shear localization for triaxialities ranging between approximately 0.3 and 0.8 [21]. Void coalescence in combined tension and shear fields has been studied numerically in Ref. [22]. However, these models need to be validated via in situ experimental 45 observations.

With the recent developments in 3D imaging techniques such as synchrotron tomography it has become possible to follow and quantify damage processes in situ at micrometer resolutions [23. Even nondestructive observations at resolutions of tens of nanometers are now possible [24, 25]. In situ tomography 50 is limited to axisymmetric (or stick-like) specimens with diameters of the order of $1 \mathrm{~mm}$, which, in practice, may be relaxed by a factor of 3 to 5 if local tomography can be used [26. In contrast, regions of interest in flat specimens can be imaged via synchrotron laminography [27, 28]. This technique has been applied to assess the underlying physical mechanisms of ductile crack initiation 

plastic yielding takes place within the band and the outer region is plastically inactive, localization has only been measured at the very latest step. However, strain concentrations in a slant strained band were observed very early on and the scene for localization and fracture was already set. It is of interest for the understanding of strain and damage interactions if this way to deform is a

and propagation 29,30 .

To evaluate 3D displacement fields in the bulk of imaged samples, two techniques are used, namely, feature tracking and volume correlation. The tracking technique consists of following the motion of particles or other features. It is performed either manually [31] or automatically [32, 33]. Digital volume correlation (DVC) provides either a cloud of 3D displacements for local-based registrations [34, 35, 36] or spatially continuous and dense displacement fields for global registrations [37, 38, 39]. For both techniques, additional markers have sometimes to be added to enable the tracking or registration procedure to be performed 40, 35, 41. However, these additional markers may alter the deformation and degradation mechanisms. Even though the volume fraction of secondary features is very low in the alloy investigated in this study (i.e., less than $1 \%$ volume fraction) it was decided not to add any additional marker since they may become damage nucleation sites. In a feasibility analysis, it has been proven that global DVC could be used to measure 3D displacement fields even under such extreme conditions [42].

For an Al-Cu-Li alloy with low work hardening it has been shown with these techniques that slant strained bands precede the onset of damage and the slant crack [43. This region of the sample has been shown to be in a plane strain state with respect to the crack propagation direction [44]. It has also been shown that the ratio between the strain in the band and outside of the band was of the order of 2 [4]. In other words the material outside the bands also deforms during every load step, except for the very last ones, but to a lesser extend than the material within the band. For the last load step deformation only occurs within the band. If the term "localization" refers to a state where general mechanism for these types of materials or only found in some particular 
cases.

In this paper the interactions between strain, porosity and the final crack are assessed via DVC for laminography data already reported in Ref. [30, namely, for a ductile aluminum alloy containing pre-existing voids (AA2139 T3). After introducing the material and the experimental approach, the strain fields and their corresponding microstructure are investigated in a region 1-mm ahead of the notch root. Incremental and cumulated strain fields will be given. The response of one void in such a strain field is then assessed. The findings are compared with a Gurson-Tvergaard-Needleman-type model simulation using shear-based void nucleation in terms of strain fields. The strain distribution will be further discussed using 2D plane strain simulations that account for soft bands or randomly distributed soft zones.

\section{Experimental configuration}

\subsection{Studied Material}

The investigated material is an Al-Cu-Mg alloy (AA2139) in a naturally aged (i.e., T3) condition. The material processing directions are the rolling direction $(\mathrm{L})$, the transverse direction $(\mathrm{T})$ and the short-transverse direction $(\mathrm{S})$ in the through thickness direction. Figure 1(a) shows the grain size (mean value: $60 \mu \mathrm{m}$ ) in the $\mathrm{L}$ direction, in the $\mathrm{T}$ (mean value: $52 \mu \mathrm{m}$ ) and $\mathrm{S}$ (mean value: $24 \mu \mathrm{m})$ directions. These data have been obtained from optical microscopy on etched sections using a mean linear intercept method [45]. Figure 1)(b) shows typical L-S and T-S sections of the material obtained by tomography. Intermetallic particles are seen in white and the aluminum matrix in gray. The intermetallic content has been determined to be $0.45 \mathrm{vol} \%$ and the initial void volume fraction $0.34 \%$ [46]. The spacing of the particles and voids has been estimated using Feret dimensions of Voronoi cells around particles and pores. The spacing is in the order of $25 \mu \mathrm{m}$ [46], which is an average upper bound.

The stress/strain curves in the $\mathrm{L}$ and $\mathrm{T}$ directions are shown in Figure 2 up to the ultimate tensile strength showing strong work hardening and high 


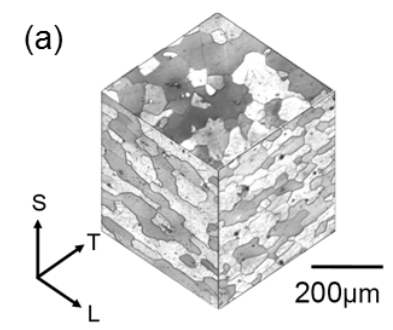

(b)
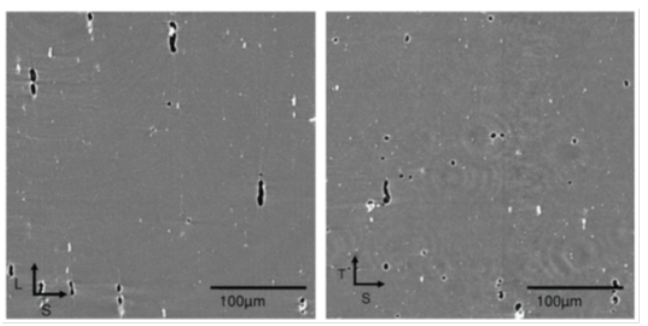

Figure 1: (a) Pseudo 3D cube showing the grain shapes (optical microscopy after etching). (b) 2D sections of reconstructed 3D synchrotron tomography data (after Ref. [45])

115 ductility (see Ref. [46] for mechanical properties and chemical composition). The material has a moderate texture and very limited anisotropy measured in stress-strain curves.

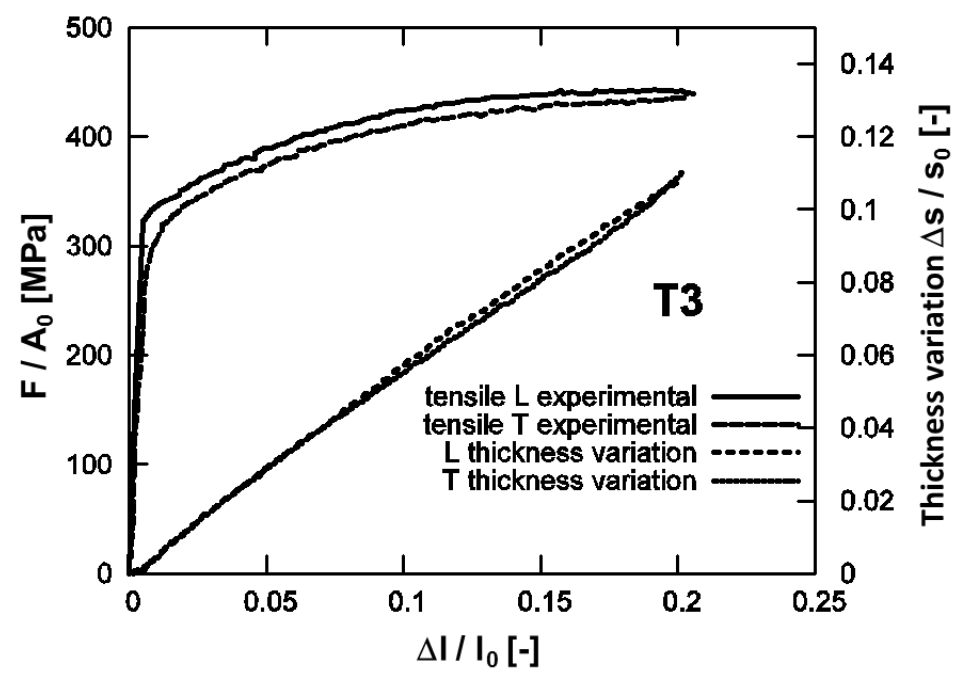

Figure 2: Engineering stress-strain curve for AA2139 T3 when loading in the L and T directions. The thickness variation is also given (after Ref. [46])

\subsection{Laminography}

Laminography imaging was performed on the instrument installed by the ${ }_{120}$ Karlsruhe Institute of Technology at the imaging beamline ID19 [47] of the European Synchrotron Radiation Facility (ESRF, Grenoble, France) in the conditions 
described by Morgeneyer et al. [30, 42]. The main advantage of laminography compared to tomography is that large flat specimens can be used. Synchrotron laminography benefits from various contrast modes including propagation-based phase contrast used herein in addition to the conventional absorption employed in laboratory X-ray imaging. For large source-specimen distances, large sample environments (e.g., mechanical testing devices) can be employed for highresolution imaging without risk of collision during the scanning motion.

Similar to tomography, a series of digital radiographs is acquired while rotating the sample about the laminographic axis [47. The latter is inclined with respect to the transmitted beam at an angle $0^{\circ}<\theta<90^{\circ}$, see Figure 3 . With the flat specimen oriented approximately perpendicular to the rotation axis, the average beam transmission can be optimized during the entire laminographic scan. Using filtered back-projection algorithms [48 different planes or complete 3D images with down to sub-micrometer resolution zoomed onto the large specimen can be reconstructed by a single scanning motion.

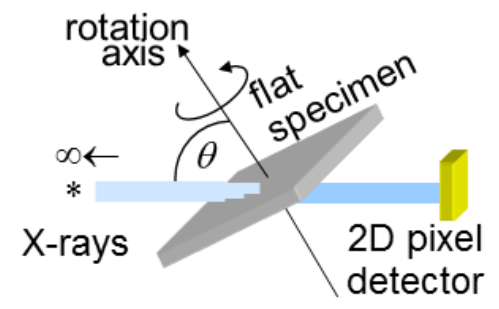

Figure 3: Schematic drawing of the laminography setup (after Ref. 42])

An inclination angle of the rotation axis of about $25^{\circ}$ with respect to the beam normal was chosen as well as a monochromatic beam of $25 \mathrm{keV}$ X-ray energy. Volumes were reconstructed from 1,500 angularly equidistant radiographs using a microscope-based indirect detector system with $\times 20$ magnification [49] and an ESRF Frelon camera. The exposure time of each projection was $250 \mathrm{~ms}$. The scanned region is $\approx 1 \mathrm{~mm}^{3}$ in volume with a voxel size of $0.7 \mu \mathrm{m}$. This is where the flat-to-slant transition is typically observed [50. The minimum specimen to detector distance is $70 \mathrm{~mm}$ leading to relatively strong edge enhancement 
due to phase contrast. The resulting strongly contrasted edges facilitate the detection of voids and damage. For easier data handling, all 3D images consisting of 32-bit floating point values were converted into 8-bit gray level 3D images using the same linear dependence. As the same affine transformation is performed after reconstruction, the gray level distributions between the images are comparable. The final reconstructed volumes have a size of $2040 \times 2040 \times 2040$ voxels. However, only the voxels where all projections contribute to the reconstruction exhibit all the directional information available, show similar noise statistics and therefore have been considered herein.

\subsection{In situ mechanical experiment}

To investigate strain and damage interactions in situ, a loading device was adapted to the environment given by the laminography scanning geometry (Figure 4(a)) 30. In particular, the device was designed to present a low profile perpendicular to the sample plane, thereby avoiding obstruction of the beam during rotation. The screws (see Figure 4(b)) allow a stepwise crack mouth opening displacement (CMOD) to be prescribed [30]. Before each "load step," the region ahead of the notch was scanned by laminography. A load step consists of turning the 2 screws of the loading device leading to incremental openings of the notch, i.e., a stepwise monotonic and quasi-static loading was applied.

The specimen (with dimensions $60 \times 70 \times 1 \mathrm{~mm}$ ) contains a round notch with a radius of $R=0.17 \mathrm{~mm}$ and a $24-\mathrm{mm}$ ligament (see Figure $4(\mathrm{~b})$ ). The loading configuration is T-L. Being close to standard tearing test geometries, this specimen provides relevant engineering conditions and allows for the development of plastic zones sizes as found in standard tests. The region ahead of the notch is loaded in tension and bending. A simple anti-buckling device (i.e., flat plates) is used to limit out-of-plane displacements.

All the mechanical parameters are characterized as functions of the nominal CMOD obtained by the opening of the loading device in this study. The definitions of CMOD, crack length $a$ are shown in Figure 4(b,d). The crack length is measured in the center of the $3 \mathrm{D}$ image/specimen and may, due to 
(a)

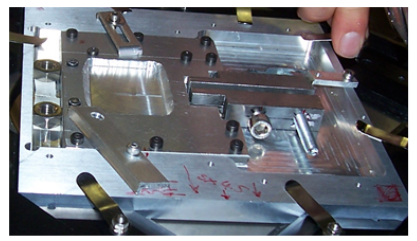

(c)

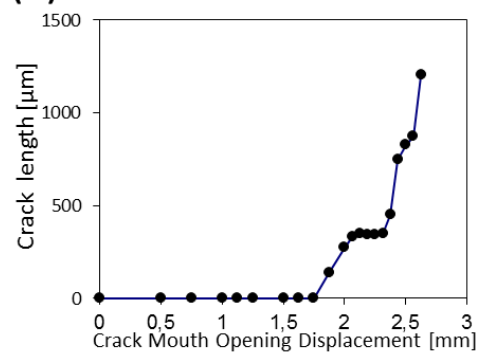

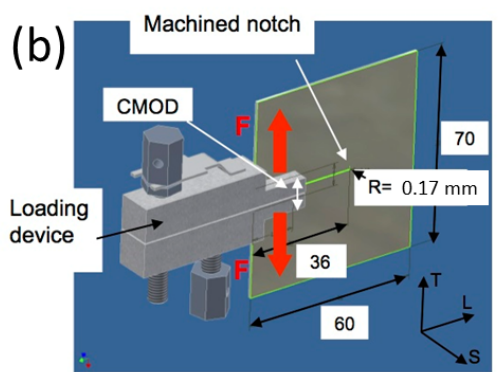

(d)

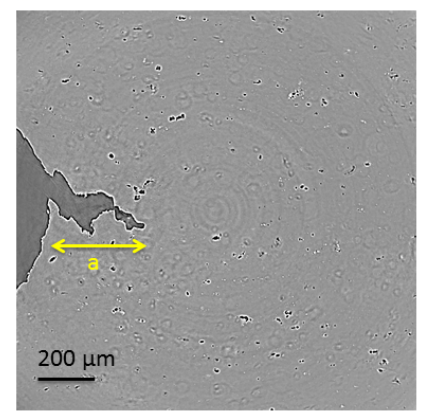

Figure 4: (a) Photograph of the specimen, loading device and anti-buckling frame mounted onto the laminography specimen holder; (b) drawing of the flat (1 $\mathrm{mm}$ ) CT-like specimen and loading device; (c) measured crack length versus CMOD curve (every dot on the curve corresponds to one load increment and corresponding scan); (d) 2D section of reconstructed laminography data at mid thickness for load step CMOD $=2.125 \mathrm{~mm}$

crack tunneling, be more accurate (and pessimistic) than traditional surface observations.

\subsection{D kinematic measurements}

The acquired scans can be used to measure 3D displacements fields by registering one gray level volume in the reference configuration $f$ and a second volume $g$ in the deformed configuration via DVC. Two different types of approaches can be followed. First local approaches consist of subdividing the region of interest (ROI) into a set of independent sub-volumes that are registered [34, 51, 35, 36]. An alternative approach is global so that the warping of the reference volume is analyzed globally and not locally [37. One of the advantages of the latter approaches is that finite element kinematics can be considered thereby allowing 
for regularized [52, 53] or integrated [54, 55] approaches.

In the following C8-DVC [37] will be considered. It consists of discretizing the volume of interest with 8-noded cubes (i.e., C8 elements) whose edge length is denoted by $\ell$. Trilinear displacement interpolations are used within each considered element. The DVC procedure consists of minimizing the global correlation residuals

$$
\Phi_{c}=\sum_{\mathrm{ROI}} \varphi^{2}(\mathbf{x})
$$

where

$$
\varphi(\mathbf{x})=|f(\mathbf{x})-g(\mathbf{x}+\mathbf{u}(\mathbf{x}))|
$$

with respect to the degrees of freedom associated with the parameterization of the displacement field $\mathbf{u}(\mathbf{x})$, where $\mathbf{x}$ denotes the location of all the voxels belonging to the ROI. The overall quality of the registration is measured by the global dimensionless residual

$$
\rho_{c}=\frac{1}{\Delta f} \sqrt{\frac{\Phi_{c}}{|\mathrm{ROI}|}}
$$

where $\Delta f=\max _{\mathrm{ROI}} f-\min _{\mathrm{ROI}} f$ denotes the dynamic range of the gray levels of the ROI in the reference configuration.

When a series of volumes in the deformed configuration is analyzed, two different strategies can be followed. First, when the strain levels remain lower than $10 \%$, the multiscale implementation [37] usually allows the whole series to be analyzed with $f$ being the volume of the first scan 38 . Second, when larger strains occur, a first step of the analysis consists of evaluating the incremental displacement fields for which the deformed volume of the previous calculation becomes the reference volume of the next one. Once this first series of calculations is performed, it is possible to cumulate the displacements in a Lagrangian way.

For example, let us denote $\mathbf{u}_{01}\left(\mathbf{x}_{0}\right)$ the displacement field of scan 1 with respect to scan 0 expressed in the reference frame of scan 0 . An incremental calculation between scan 1 and 2 will yield the displacement field $\mathbf{u}_{12}\left(\mathbf{x}_{1}\right)$ expressed in the frame of scan 1 . To be cumulated, the incremental displacement 
field $\mathbf{u}_{12}$ has to be evaluated for the location of $\mathbf{x}_{0}$ in the deformed configuration $\hat{\mathbf{x}}_{1}\left(\mathbf{x}_{0}\right)=\mathbf{x}_{0}+\mathbf{u}_{01}\left(\mathbf{x}_{0}\right)$. Knowing the measured displacement field $\mathbf{u}_{12}\left(\mathbf{x}_{1}\right)$, it can be interpolated to be evaluated at $\hat{\mathbf{x}}_{1}$ by using the shape functions of the $\mathrm{C} 8$ discretization. Let $\hat{\mathbf{u}}_{12}$ denote this interpolated displacement field. The cumulated displacement field then reads

$$
\mathbf{u}_{02}\left(\mathbf{x}_{0}\right)=\mathbf{u}_{01}\left(\mathbf{x}_{0}\right)+\hat{\mathbf{u}}_{12}\left(\mathbf{x}_{0}\right)
$$

with

$$
\hat{\mathbf{u}}_{12}\left(\mathbf{x}_{0}\right)=\mathbf{u}_{12}\left(\mathbf{x}_{0}+\mathbf{u}_{01}\left(\mathbf{x}_{0}\right)\right)
$$

In general, some of the nodal positions may require an extrapolation, namely, they lie outside the ROI in the reference configuration. In that case, among many options, two are implemented. If the aim is to stop the analysis at this stage, no extrapolation is required, they are considered as $\mathrm{NaN}$ (i.e., not a number) and they are not visualized. Direct calculations may also be performed in which this first evaluation of the cumulated displacement field corresponds to the initial guess of a direct calculation from scan 0 to 2 [3]. In that case, the previous option cannot be used and extrapolated values should be assessed. The extrapolated value corresponds to the displacement of the closest node for which a measured estimate exists.

In the present DVC analyses, a volume of interest has been extracted from the scanned volume. Within this volume an initial ROI of $864 \times 608 \times 992$ voxels ${ }_{210}$ (i.e., $\approx 600 \mu \mathrm{m} \times 425 \mu \mathrm{m} \times 700 \mu \mathrm{m}$ ) has been considered for correlation purposes and has been discretized with 32 -voxel C8 elements. With such a discretization, $\approx 54,000$ kinematic degrees of freedom are measured. The choice of the element size in any DVC calculation results from a compromise between measurement uncertainty and spatial resolution [56, 42] (here twice the element size, i.e., ${ }_{215} \approx 45 \mu \mathrm{m}$ ). To evaluate the resolution of the measurement technique, two scans of the undeformed configuration were reconstructed when a small motion was prescribed between the two acquisitions. For 32-voxel $(\approx 22 \mu \mathrm{m})$ elements, the standard displacement resolution was found to be of the order of 0.2 voxel, and the corresponding standard equivalent strain resolution equal to $0.5 \%$. 

distinguished from noise. From the loading state CMOD $=2.313 \mathrm{~mm}$ onward, the ROI was shifted away from the notch by $280 \mu \mathrm{m}$ to avoid the damaged region and reach correlation convergence. In addition, a bigger ROI has been used (i.e., $1248 \times 512 \times 992$ voxels) to be able to follow two voids in the microstructure in 225 spite of large strain levels.

Based upon these results, the convergence criterion of the correlation calculations, which corresponds to the mean displacement increment between two consecutive iterations, is chosen to be equal to $10^{-4}$ voxel. It was checked that the mean correlation residual has reached a steady state for this criterion. The results are also checked by computing the correlation residuals voxel-wise, and their average value (i.e., $\Phi_{c}$ or equivalently $\rho_{c}$ ). The mean and local residual levels are similar to those found by considering two subsequent acquisitions in which no deformation of the sample has occurred (i.e., for the resolution analysis). Consequently, the reported results are deemed trustworthy.

The correlation analyses reported herein consist of estimating the total displacement field for each analyzed step with respect to the reference configuration up to loading step for which the CMOD is equal to $1.625 \mathrm{~mm}$. From these Lagrangian measurements, the incremental displacement fields are directly given by the total displacement difference corresponding to two consecutive steps. The Green-Lagrange strain fields are estimated either with the total displacement fields, or with the incremental displacement fields. In both cases, the mean values per $\mathrm{C} 8$ element are reported. For the displacement field between the initial state and any load step for which the CMOD is greater than $1.5 \mathrm{~mm}$ the direct correlation could not yield a converged solution as strains are very high and damage nucleation started to set in. For this reason incremental correlations taking load state $\mathrm{CMOD}=1.5 \mathrm{~mm}$ as a reference have been carried out. This procedure was also performed for the subsequent load steps. 


\section{Strain and damage interaction}

\subsection{Incremental fields}

Several parallel slant bands are observed at this relatively early stage of loading. Three bands oriented from the lower left part of the section to the upper right 


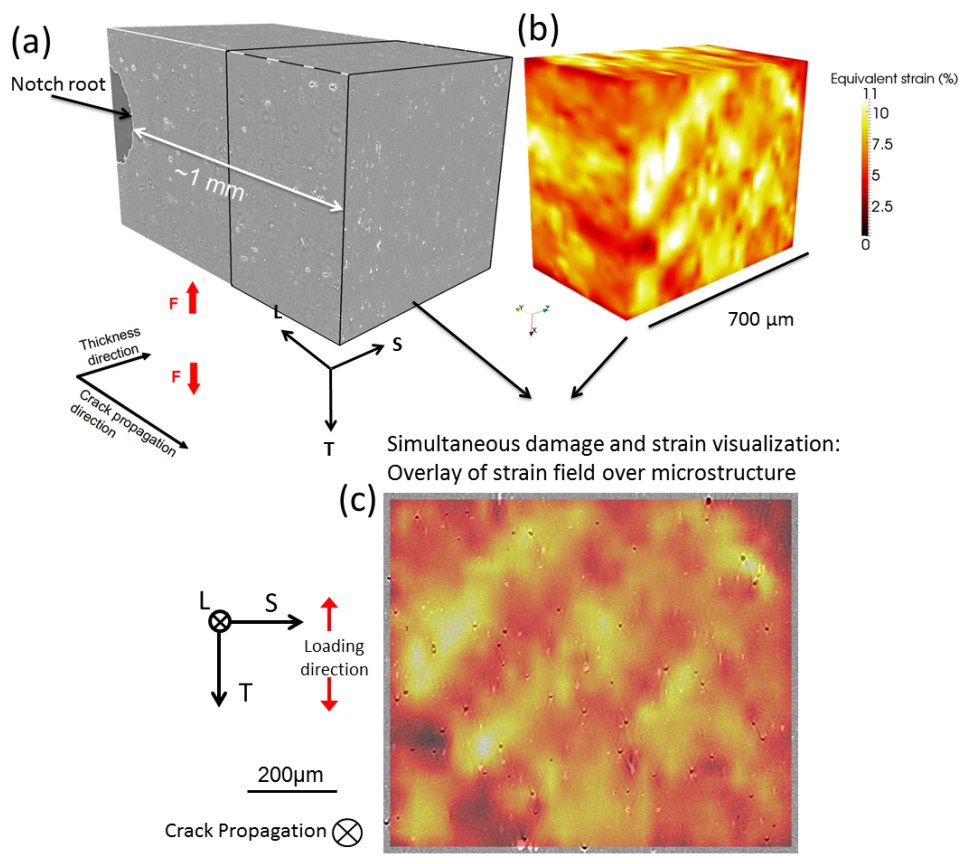

Figure 5: (a) 3D rendering of the initial microstructure and the ROI. (b) 3D rendering of the equivalent strain field in the extracted volume when CMOD $=1.5 \mathrm{~mm}$. (c) $2 \mathrm{D}$ overlay of strain field over the initial microstructure

part seem to be prevalent. In this $2 \mathrm{D}$ section no clear link between the underlying voids and the strained bands is established. The magnitude of the strain in the bands is about twice as high (i.e., $13 \%$ ) as in the material between the bands. This ratio has already been found for an aluminum alloy with less work hardening and initial porosity [43. However, the latter material mainly showed one localized band and not several parallel bands as seen here. In addition, the slant strained band was less diffuse than in the present case. On this $2 \mathrm{D}$ section two particular voids of the underlying microstructure are encircled. They are also highlighted for the following load increments. This representation allows the spatial location of the strained bands to be assessed with respect to their underlying microstructure and if these bands "stick" to the microstructure.

In Figure 6(b) an overlay of the incremental strain field between CMOD $=1.5 \mathrm{~mm}$ and $\mathrm{CMOD}=2.0 \mathrm{~mm}$ is shown over the underlying microstructure of the load 


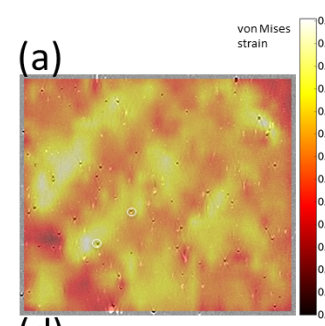

(d)

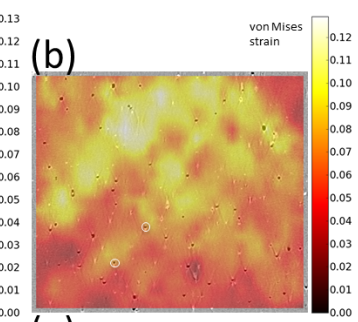

(e)
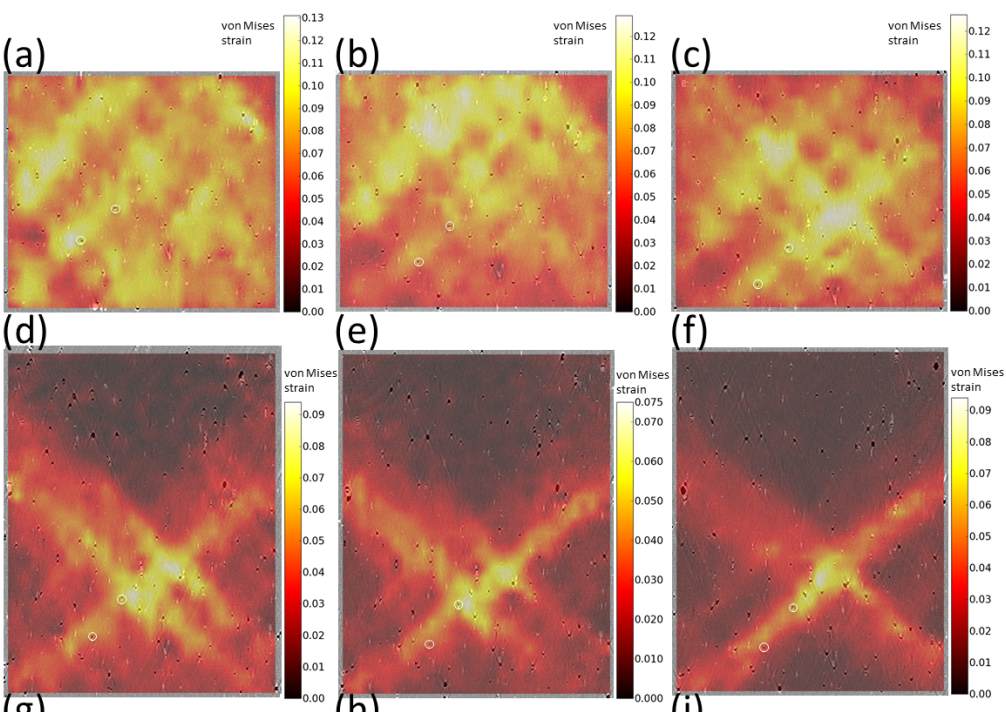

(f)

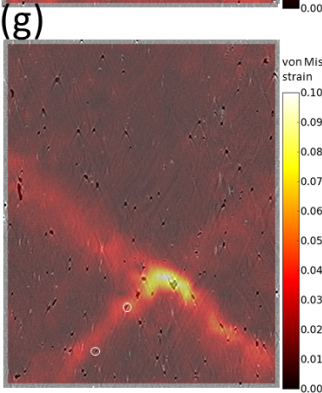

(h)
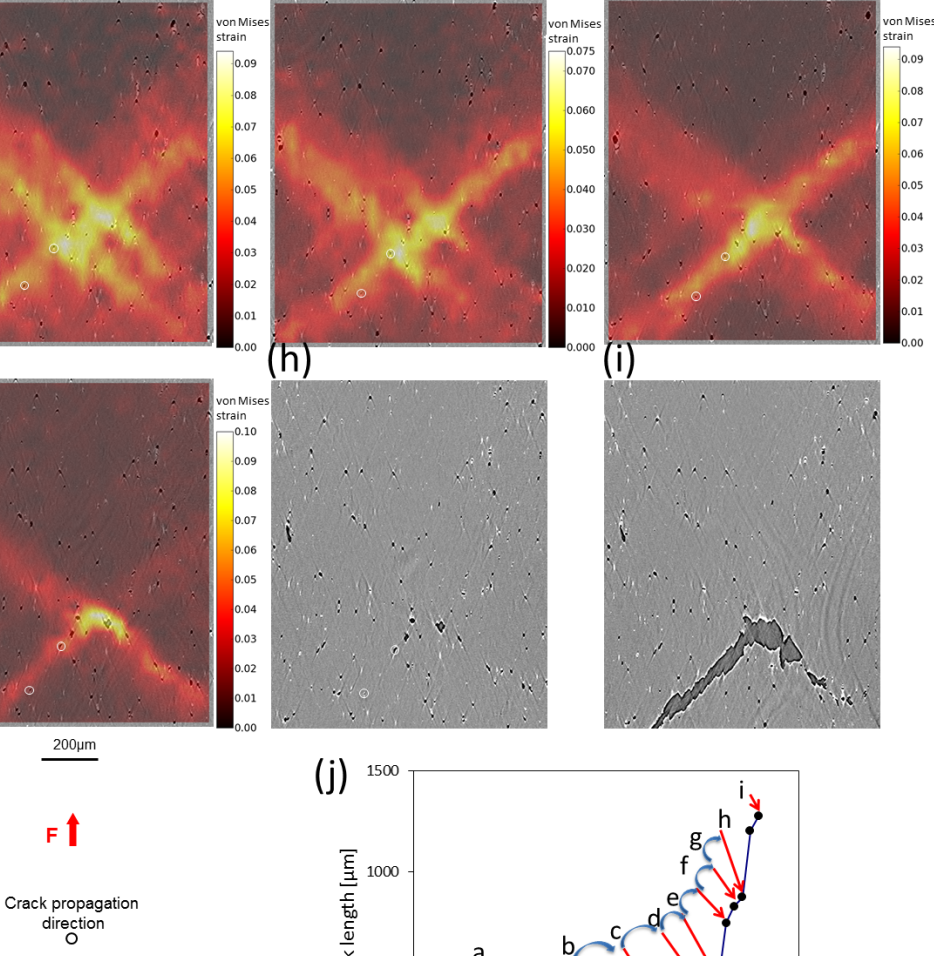

$\mathrm{F} \downarrow$
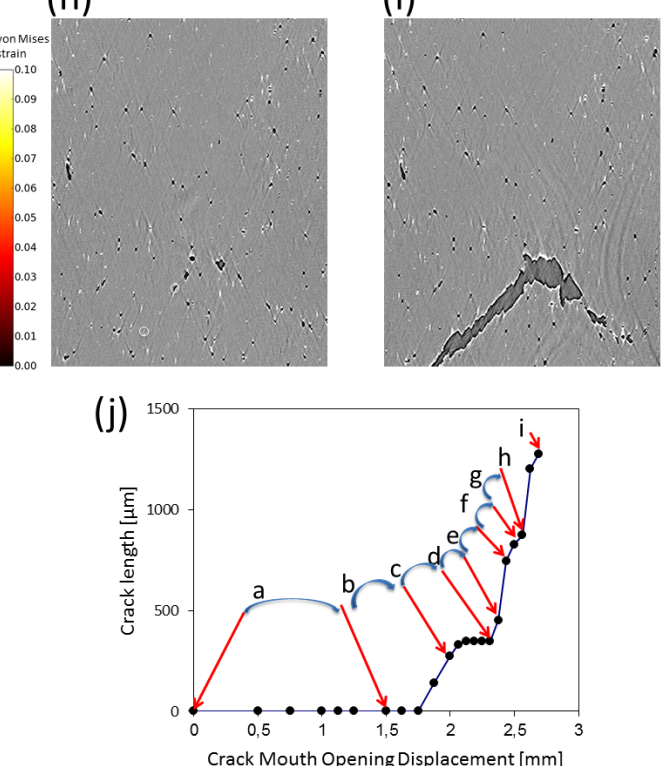

Figure 6: Overlay of incremental equivalent strain fields (half transparent) over the microstructure $1080 \mu \mathrm{m}$ ahead of the notch root. (a)-(g) 2D sections of laminography data and equivalent strain fields. The microstructure is shown in state $n$ for incremental correlations between $n$ and $n+i$. Two reference voids are encircled in white on the microstructure for every load step; (h),(i) microstructure showing damage and the final crack path; (j) load steps corresponding to the shown sections 
step corresponding to $\mathrm{CMOD}=1.5 \mathrm{~mm}$. Out of the three slant strained bands that were active in the first load step the upper one is the most active. The other two bands are less active. Compared to Figure 6(a) the strained band has shifted downward, but this is only due to a shift of the entire region of local strains as the crack approaches this region. From the lower left part of this region to the upper right part only one strained band is active (Figure 6(d)). It is still located above the two encircled voids. Normal to this band two other parallel strained bands are active. The strain field is now substantially more 320 load step from CMOD $=2.375 \mathrm{~mm}$ to $\mathrm{CMOD}=2.438 \mathrm{~mm}($ Figure 6(e)). There 
is still very little damage to be seen in the microstructure at this location and, if any, it is rather diffuse and also located in regions that do not belong to any strained band.

In Figure 6(f) the same strained band from the lower left to the upper right corner of the image is mainly active. Only one out of the two bands normal to this one, i.e., the upper band, is now active. The latter is particularly active in the lower part of the investigated region. It is noteworthy that at these late stages of loading there is still not only a single strained band active but a competition between several bands that have undergone tens of percents of strain. The next load step from CMOD $=2.438 \mathrm{~mm}$ to $\mathrm{CMOD}=2.5 \mathrm{~mm}$ is the last one for which a trustworthy correlation could be achieved (Figure 6(g)), namely, the residuals were still very close to those observed when two undeformed volumes are registered. It can be seen for the underlying microstructure that a notable damage evolution now sets in. In the region where the strained bands cross, voids grow. The upper one of the two encircled voids shows a reorientation that has already been reported [50] for the same experiment. With the present work the corresponding strain fields for the void shape changes are known.

Figure 6(h) shows the microstructure of load step CMOD $=2.5 \mathrm{~mm}$ without the corresponding strain field. Voids in the region where the two strained bands cross grow further. This highlights that in this area the main assumption for trustworthy DVC, which is the conservation of gray levels is no longer satisfied as damage sets in. However, the measured strain concentration where the two strained bands cross is plausible, as, in addition, void growth is seen here that is surely a result of highly localized strain activity. The lower half of the strained bands is more active than the upper half. In Figure 6(i) the final crack path is observed (i.e., $\mathrm{CMOD}=2.625 \mathrm{~mm}$ ). A roof top crack is seen, which has not fractured the full section yet. The crack has followed the second slant strained band that is present from the very early loading onward. The two voids that 350 had been encircled in the previous load increments now contribute to the final fracture surface.

In summary, several slant, crossing and parallel strained bands with inter- 
mittent activity were found. Failure occurred along one band that was already active since the very beginning of the loading history. to softening.

The strain profile along a line perpendicular to the strained bands is shown 

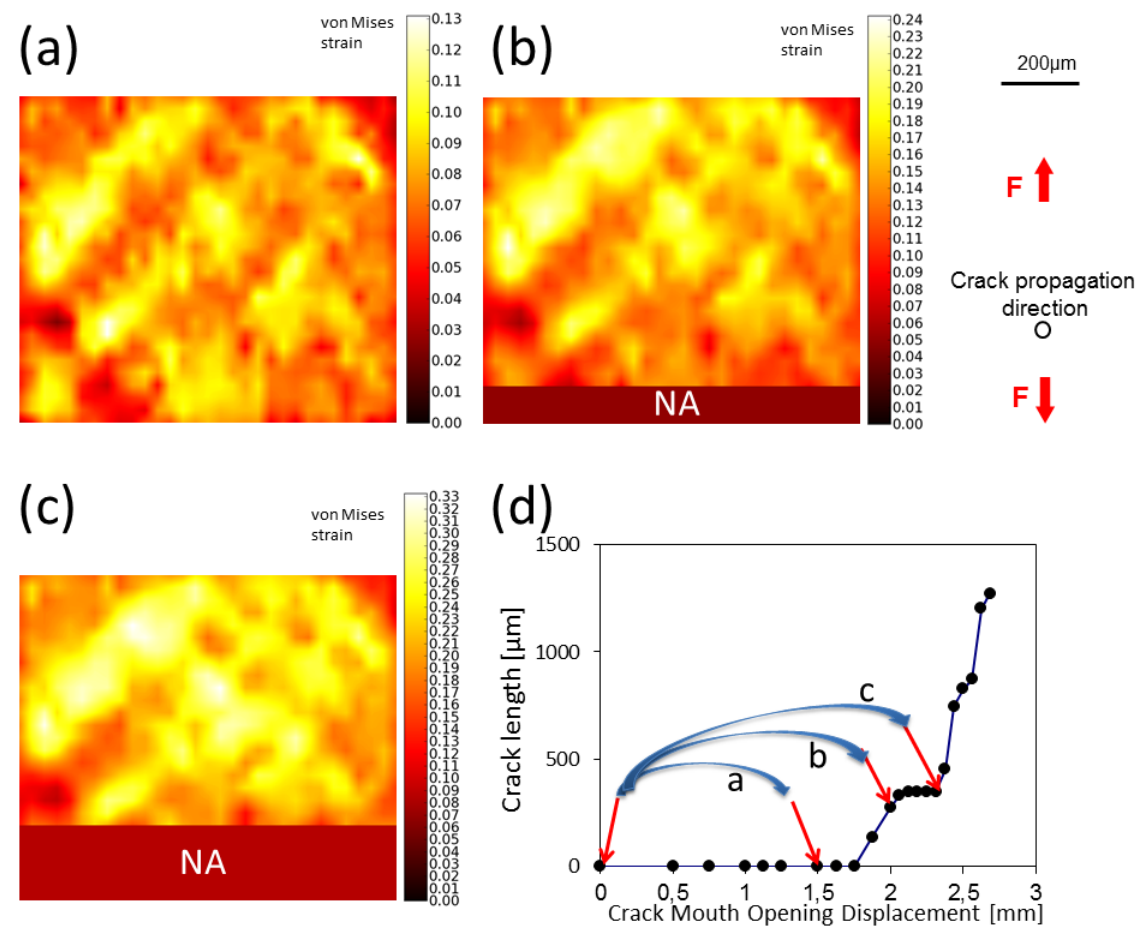

Figure 7: 2D sections of cumulated equivalent von Mises strain fields. (a) Direct correlation from $\mathrm{CMOD}=0.0 \mathrm{~mm}$ to $\mathrm{CMOD}=1.5 \mathrm{~mm}$. (b) One cumulation from $\mathrm{CMOD}=0.0 \mathrm{~mm}$ to CMOD $=2.0 \mathrm{~mm}$. (c) Two cumulations from $\mathrm{CMOD}=0.0 \mathrm{~mm}$ to $\mathrm{CMOD}=2.313 \mathrm{~mm}$ (the coordinate system is shown in its initial state)

in Figure 8 This graph confirms the spatial stability of the strained bands. The ratio of the equivalent strain in the main bands over the strain outside the bands lies between 1.5 and 2. For the band that will lead to the final failure this ratio is somewhat lower. This result is comparable to the strain ratio that was reported for AA $2198 \mathrm{~T} 8$ [4]. The main difference is that several bands are active in the present case.

\subsection{Small load increments from the initial state}

In this section strain fields for small steps are reported when DVC is performed from the unloaded step $(\mathrm{CMOD}=0.0 \mathrm{~mm})$ to the load step before crack initiation (i.e., $\mathrm{CMOD}=1.5 \mathrm{~mm}$ ). The incremental strain fields in this load 
(a)

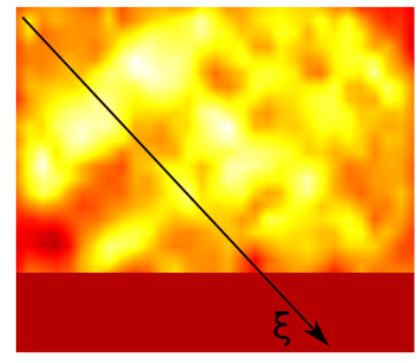

(b)

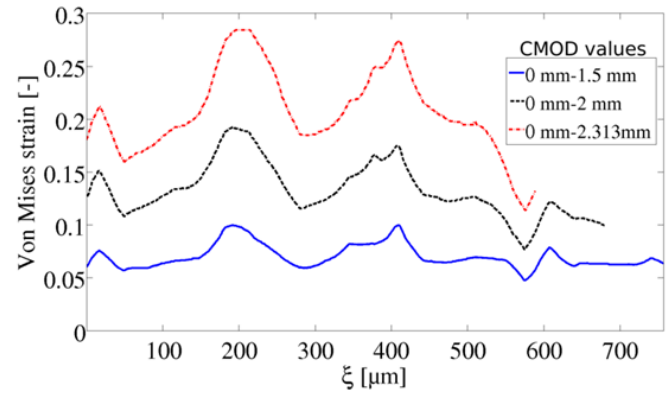

Figure 8: (a) 2D section of cumulated fields (equivalent von Mises strain) with indication of the location for the strain profile. (b) Strain profile for the direct and cumulated strain fields from CMOD $=0.0 \mathrm{~mm}$ to $\mathrm{CMOD}=2.313 \mathrm{~mm}$

interval from the unloaded state are also given. The latter investigation is made in order to interpret the incremental strain activity $\left(\Delta \mathrm{p}_{e q}\right)$ as could also be done in an FE simulation that accounts for instabilities.

Figure 9 (a) shows the strain field obtained for the first load step carried out during the in situ test (i.e., $\mathrm{CMOD}=0.5 \mathrm{~mm}$ ). In this step a maximum equivalent strain of 0.03 is obtained. However, the three strained bands from the lower left corner of the image to the upper right corner can already be seen. These bands remain visible for a substantially larger load increment (Figure 6(a)). Damage nucleation or growth is negligible at this step of loading. A similar result was also found for AA2198 T8 [43. The strained bands found herein are less localized.

Figure 9 (b) shows the strain field for a correlation from the initial unloaded state to the second load step (i.e., CMOD $=0.75 \mathrm{~mm}$ ). The strain field has a similar pattern as the first one, but the strain magnitude increases up to 0.05. For the subsequent load steps (Figures 9 (c-f)) the same observation holds. It should be noted that the last strain field (see Figure $9(\mathrm{f})$ ) is the same as that shown in Figure 6(a). This result indicates that the characteristic strain pattern hardly evolves over the loading history, which is also consistent with the very large strain measurements shown in Figure 7 
(a)

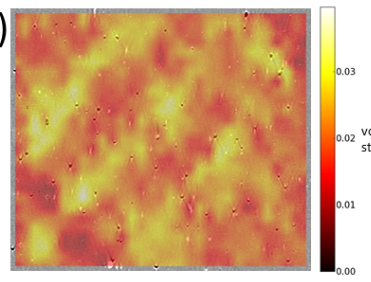

(c)

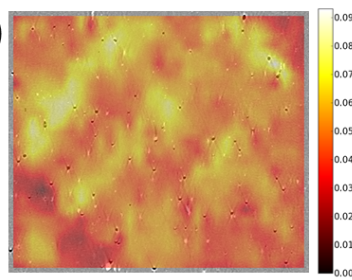

(e)

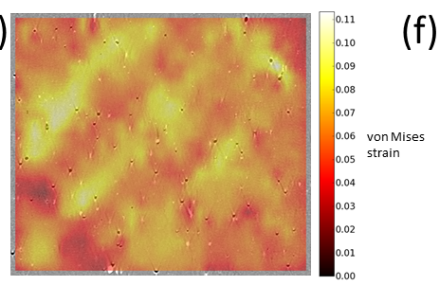

(g)

(g) (b)

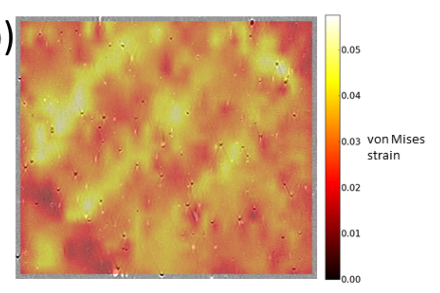

(d)

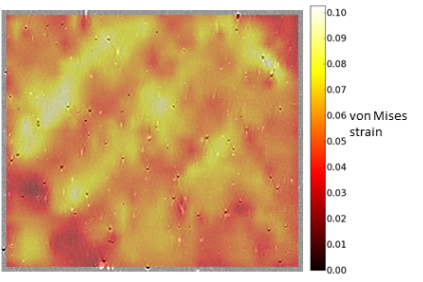

(f)

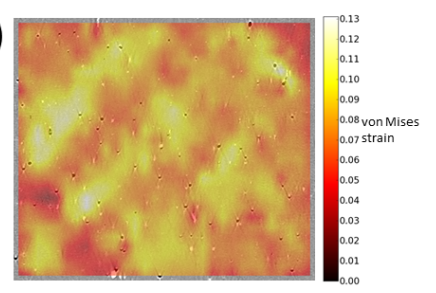

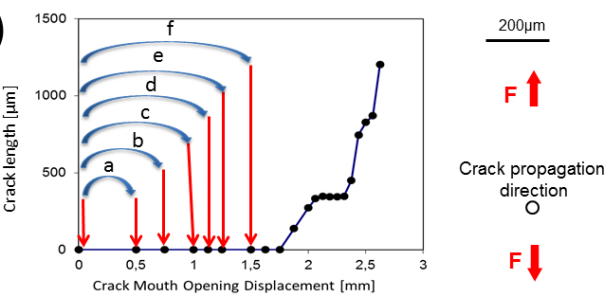

Figure 9: 2D section of 3D laminography and DVC data. Overlay of the smallest possible direct equivalent strain fields (half transparent) over the microstructure in its initial state

Incremental strain fields are shown in Figure 10 in the undeformed coordinate system of the initial material microstructure. Figure 10(a) shows the same strain field as Figure 6(a). The subsequent strain fields, in contrast, have an intermittent activity. In Figure 10(b) the next incremental strain field is reported. The noisy nature of the field is due to a lower signal to noise ratio of the measurements (i.e., the maximum strain is about 0.02). The three strained bands can still be guessed. In the subsequent load step the upper strained bands seem more active than the lower ones. The next three incremental fields appear 
(a)

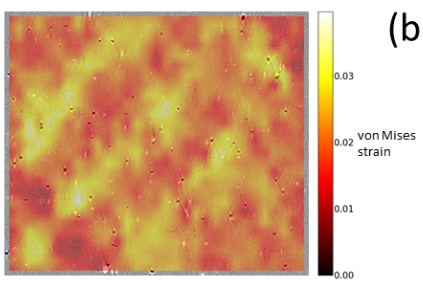

(c)

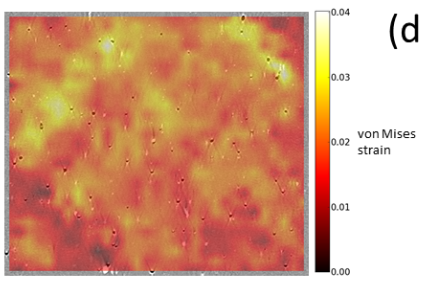

(e)

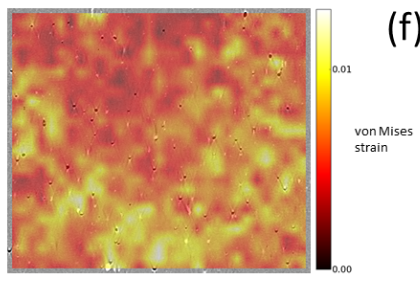

(g)

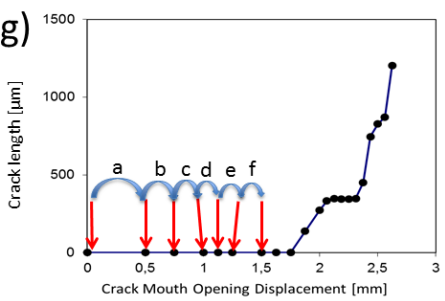

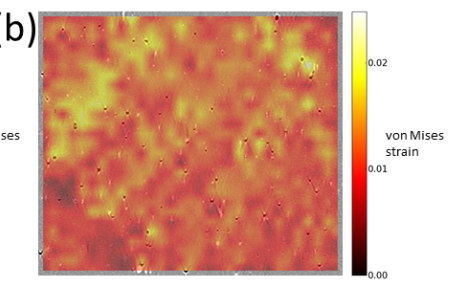

(d)

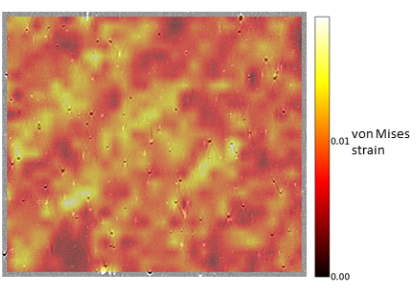

(f)

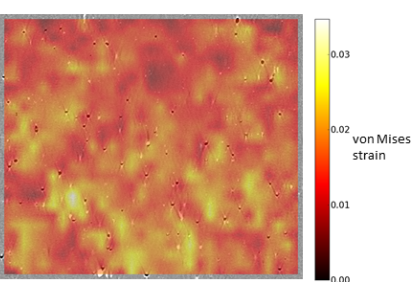

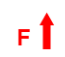

Crack propagation direction

$\mathrm{F} \downarrow$

Figure 10: 2D section of 3D laminography and DVC data. Overlay of the smallest possible incremental equivalent strain fields (half transparent) over the microstructure in its initial state noisy due to the low maximum strain level (as low as 0.02 for Figure 10(d)). However, the strain activity is higher in the lower part of the field.

In Figure 11, incremental strain fields in the same loading interval $(\mathrm{CMOD}=0.0 \mathrm{~mm}$ to $\mathrm{CMOD}=1.5 \mathrm{~mm}$ ) are also given. However, bigger load increments are assessed in the correlation $(n$ to $n+2)$ to obtain a higher signal to noise ratio.

${ }_{425}$ Figure 11(a) corresponds to Figure 9(b). The three strained bands are visible. Figure 9 (b) shows the incremental strain field from load step CMOD $=0.75 \mathrm{~mm}$ 
to $\mathrm{CMOD}=1.125 \mathrm{~mm}$. A similar strain pattern as in the initial step is observed. The strain activity is somewhat higher in the upper part of the region. In Figure 11(c) the largest strain activity is seen in the lower part of the 2D section. This activity may be consistent with Portevin Le Chatelier (PLC)-like behavior spreading the strain in an even manner. However, the characteristic strain pattern always remains, i.e., most of the strain activity takes place in the strained bands and not in the surrounding strain "valleys."

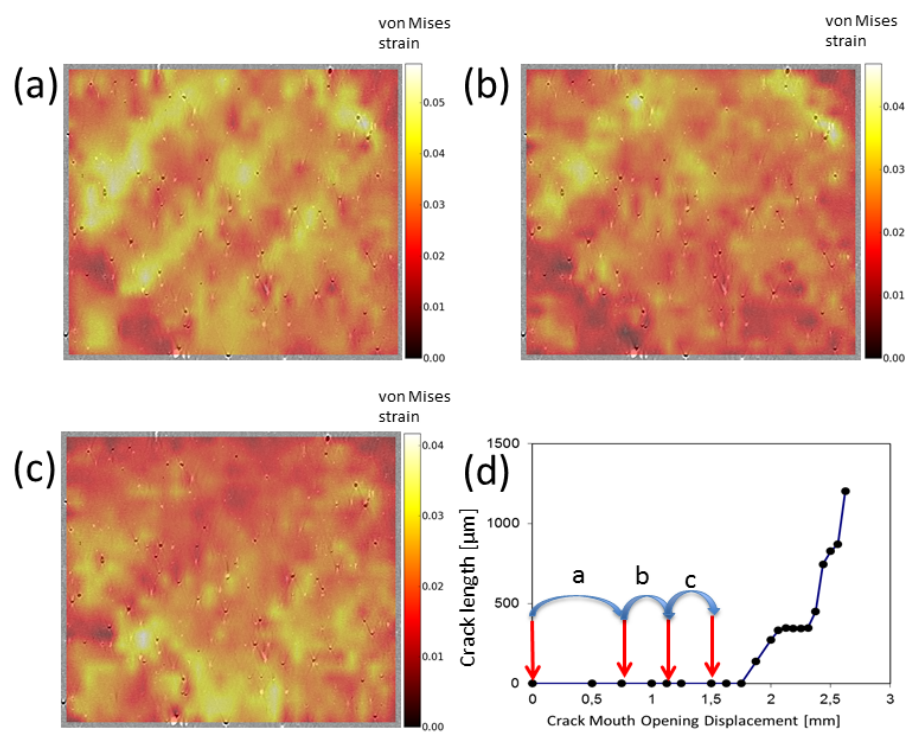

Figure 11: 2D section of 3D laminography and DVC data. Overlay of incremental equivalent strain fields $n$ to $n+2$ (half transparent) over microstructure (the microstructure in its initial state)

In Figure 12 the strain field for incremental steps from CMOD $=0.0$ to $\mathrm{CMOD}=1.0 \mathrm{~mm}($ Figure $12(\mathrm{a}))$ and from $\mathrm{CMOD}=1.0 \mathrm{~mm}$ to $\mathrm{CMOD}=1.5 \mathrm{~mm}$ (Figure 12(b)) are reported. The three strained bands are again observed in Figure 12(a). In Figure 12(b) it can be seen that the strain activity is more pronounced in the lower part of the $2 \mathrm{D}$ section. This behavior has already been seen in Figure 11(c) and might be attributed to PLC-like effects. 

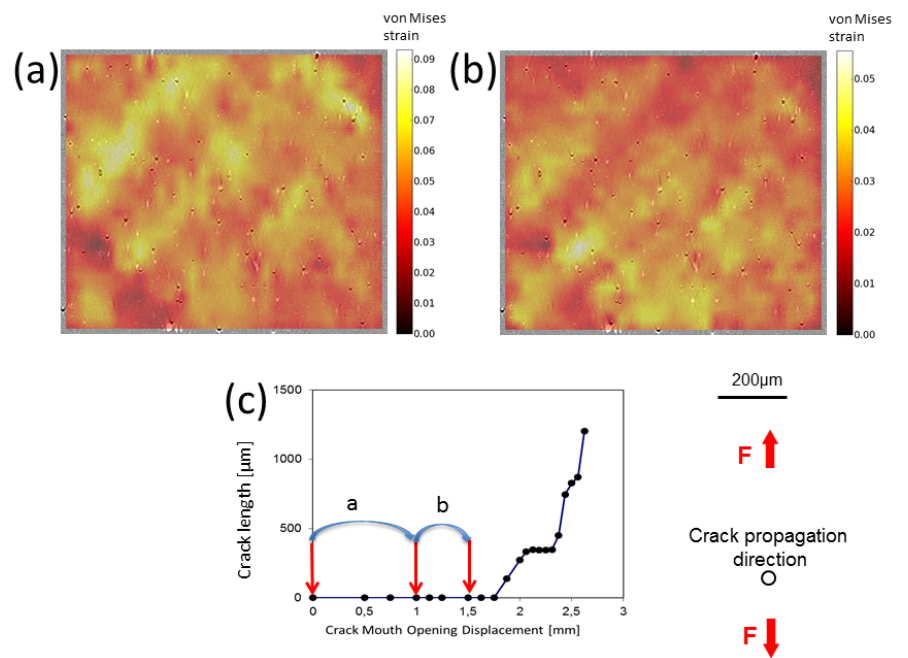

Figure 12: 2D section of 3D laminography and DVC data. Overlay of incremental equivalent strain fields $n$ to $n+3$ (half transparent) over the microstructure in the initial state

\subsection{Void shape evolution in strained bands}

In previous sections the existence of intermittent strained bands has been shown. In this section the interest lies on the evolution of a pre-existing void (i.e., hydrogen micropore [57]) up to fracture in such a strained band. The void is located $45 \mu \mathrm{m}$ farther away from the notch than the $2 \mathrm{D}$ section shown in the previous figures. It is situated at about mid-thickness of the specimen (see Figures $13(\mathrm{a}-\mathrm{b})$ [50]). This void was located in the final strained band that led to fracture as illustrated by the overlay of the strain field over the underlying microstructure (Figure 13(b)). It undergoes substantial growth only at late stages of deformation. From Figure 77(c) it is known that the corresponding equivalent strain is of the order of 0.30 in this region, but growth is moderate as seen in Figure 13(e).

In the subsequent load steps the void grows in the loading direction and turns toward the orientation of the strained band. During the next load steps, void growth mainly occurs along the strained band direction. This is consistent with a local mode I and III loading state 9 that lets the void grow in a mixture of tensile and simple shear fields 21]. This void reorientation has been shown 


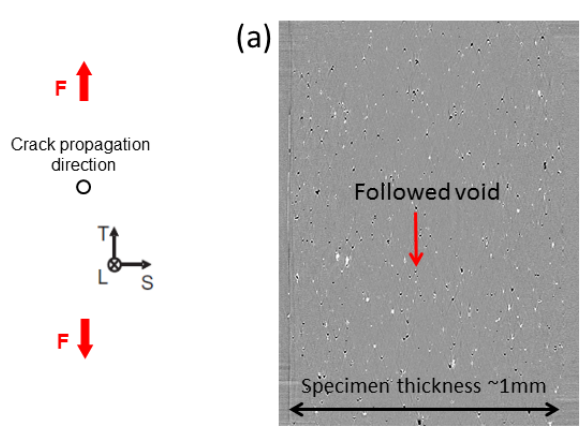

(c)

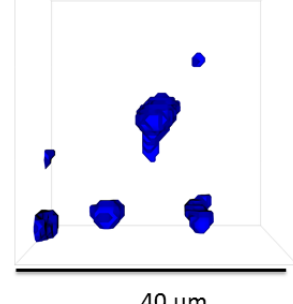

(f)

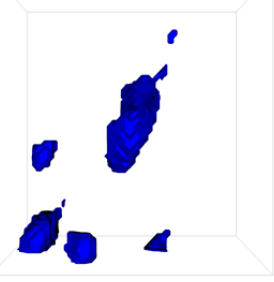

(i)

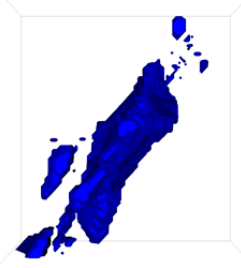

(d)

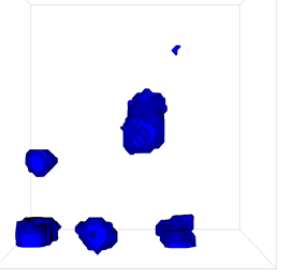

(g)

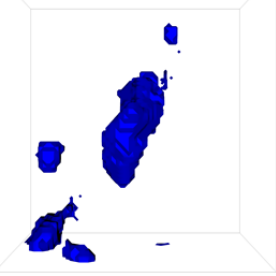

(j)

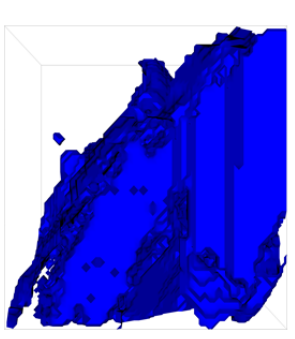

(b)

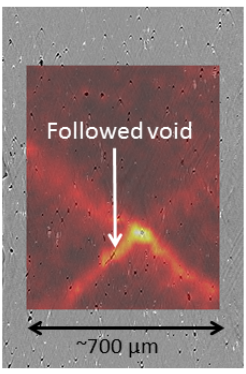

(e)

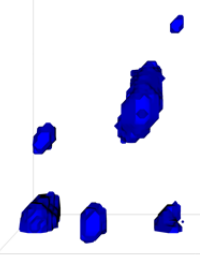

(h)
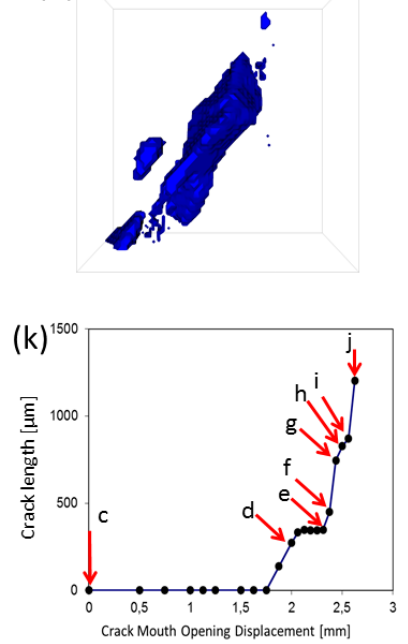

Figure 13: 3D void visualization of reconstructed laminography data. (a) Through-thickness section with location of the void $1125 \mu \mathrm{m}$ from the notch. (b) Overlay of strain field for step $\mathrm{CMOD}=2.5 \mathrm{~mm}$ to $\mathrm{CMOD}=2.563 \mathrm{~mm}$ over microstructure at $\mathrm{CMOD}=2.5 \mathrm{~mm}$. (c)-(j) Void growth. (k) Indication of the corresponding load step 
numerically to facilitate localization phenomena. In the final stages smaller damage features become visible that are consistent with void nucleation and growth on a second population of particles at high levels of strain. However, very narrow crack regions are also seen in Figure 13(i), which are consistent with the void sheeting phenomenon. This void fully contributes to the final crack.

The void growth versus local equivalent von Mises strain has been further quantified in Figure 14. This figure confirms that despite the fact that the

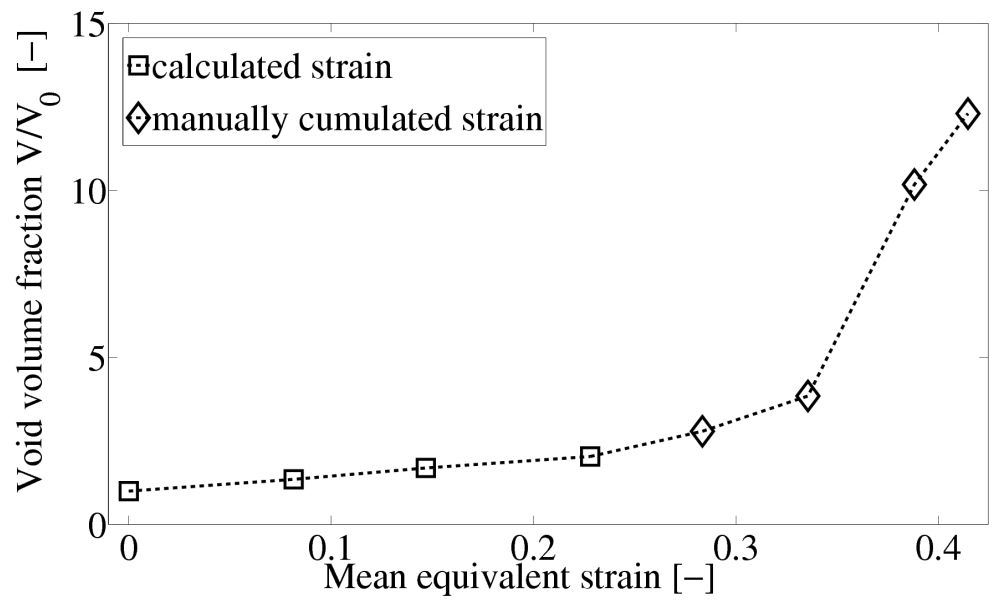

Figure 14: Void volume fraction for one void (see Figure 13) versus measured von Mises equivalent strain.

strain profiles are already heterogeneous from early loading stages onward no substantial void growth occurs until elevated levels of strain (more than 0.30 in the present case). This is also in agreement with results obtained by unit cell calculations [46. They predict for a stress triaxiality of 1.25 a void volume (vv) of 3 times the initial volume at about $0.15-0.35$ strain. However, void coalescence is predicted in unit cell calculations at higher void volume fraction level than in the experiment (about 12 times the initial vv) and also at higher strain (0.3-0.5). In the experimental data void growth acceleration occurs at 0.3 strain and for a vv that is 3 times higher than the initial one, i.e., substantially earlier than in the unit cell calculations. The complex strain field encountered 
herein, which may lead to mixed tensile and shear states, may be at the origin

of this behavior [21. It is worth noting that only one void has been studied. An investigation considering more voids would be useful to gain a better statistical representation of these processes.

\section{Simulations}

To interpret these experimental results, and in particular the slant strained band formation at early loading stages, simulations are carried out. In Ref. [50] Gurson-Tvergaard-Needleman-type simulations consistent with the experimentally observed crack growth have been carried out for the present material and sample geometry. These simulations did not show inclined bands in the strain fields nor slant fracture. A shear-based void nucleation term is used [12, which had yielded slant fracture, to compare the initial measured and predicted strain fields and final fracture.

\subsection{D Gurson-Tvergaard-Needleman-type simulations}

The modification for void nucleation under shear [12] is briefly recalled. The idea is to use the Lode parameter of the strain rate tensor to detect if the material deforms under a shear strain state and nucleate voids in that case. The Lode parameter for the strain rate tensor assuming incompressibility reads

$$
\dot{\pi}=\frac{3 \dot{p}_{2}}{\dot{p}_{1}-\dot{p}_{3}} \text { with } \dot{p}_{1} \geq \dot{p}_{2} \geq \dot{p}_{3}
$$

where $\dot{p}_{i}$ are the eigen values of the plastic strain rate tensor. Using the Lode parameter of the strain rate tensor, the shear-controlled nucleation rate is then expressed as

$$
\dot{f}_{n}=A_{n} \dot{p}
$$

with

$$
A_{n}=A_{2}^{\text {shear }} \exp \left[-\left(\frac{\dot{\pi}}{\dot{\pi}_{0}}\right)^{2}\right] \text { when } p \geq p_{\text {crit }}^{\text {shear }}
$$


where $\dot{\pi}_{0}$ is an adjustable parameter of the Gaussian function. For the rest of the Gurson-Tvergaard-Needleman-type model the reader is referred to Refs. [46, 12, The model parameters are given in Table 1.

Table 1: Material parameters for the laws used herein

\begin{tabular}{|l|l|l|l|l|l|l|l|l|}
\hline \multicolumn{1}{|l|}{ Behavior } \\
\hline Elastoplastic & $\mathrm{E}(\mathrm{GPa})$ & $\nu$ & $R_{0}(\mathrm{MPa})$ & $K_{0}$ & $K_{1}$ & $k_{1}$ & $K_{2}$ & $k_{2}$ \\
& 70 & 0.3 & 250 & 0.054 & 1.12 & 7.15 & 0.273 & 187 \\
\hline Damage & $q_{1}$ & $q_{2}$ & $f_{0}$ & $f_{c}$ & $A_{n}^{1}$ & $A_{n}^{\text {shear }}$ & $p_{c}^{\text {shear }}$ & $\dot{\pi}_{0}$ \\
& 1.97 & 0.91 & $0.33 \%$ avg. & $4.5 \%$ & 0.05 & 2.0 & 0.1 & 0.033 \\
\hline
\end{tabular}

The results of the simulations with the new term for void nucleation are shown in Figure 15. The strain fields are given in the same ROI as the measured fields. For some increments the strain magnitude is different from the experiment. It can be seen that the initial simulated strain fields do not resemble the measured ones. The simulated strain fields resemble those of von Mises-type plasticity simulations or classical Gurson-Tvergaard-Needleman-type simulation [43] with a characteristic circular strain pattern. This is expected as the shear nucleation terms only sets in after a critical strain of 0.10 . Only at late stages do the strain fields begin to be slanted. In contrast to the experimental findings only one band is active and not several parallel strain bands with intermittent activity. The slant fracture and flat-to-slant crack transition are successfully reproduced in this simulation. The fact that the initial strain fields are not found by the simulation indicates that the plasticity model needs to be modified to enhance the predictions.

\subsection{Effect of material heterogeneity}

\subsubsection{Soft slant bands}

The measurements of the strain fields ahead of the notch show parallel strained bands that are stable in space but have intermittent activity. The ratio of the strains within the bands and outside is of the order of 1.5-2.0 (see 
(a)

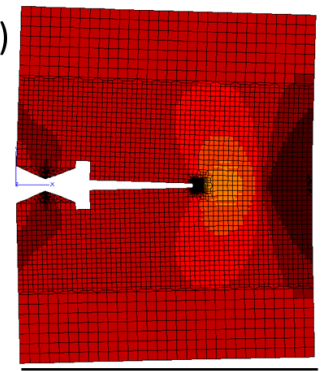

(c) $60 \mathrm{~mm} \quad \Delta p \quad$ (d)

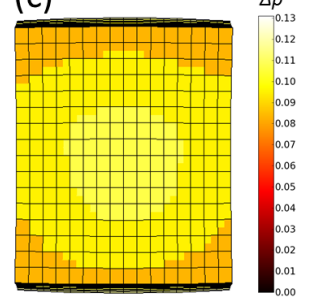

(f)

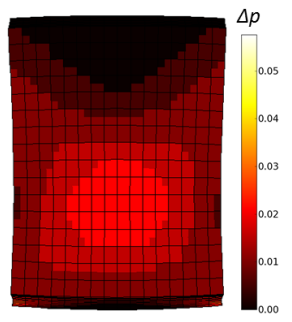

(i)

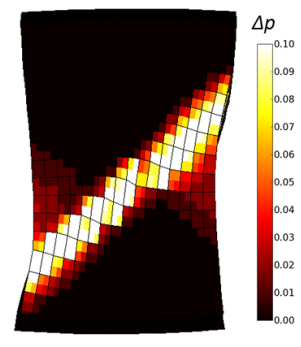

$800 \mu \mathrm{m}$
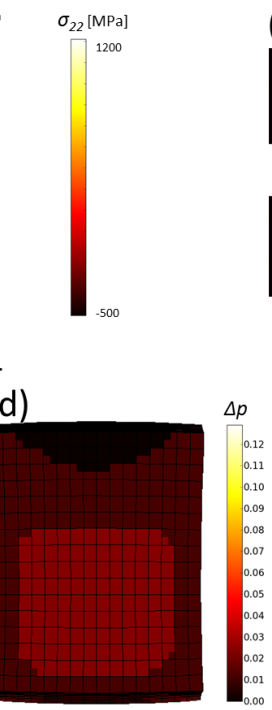

(g)

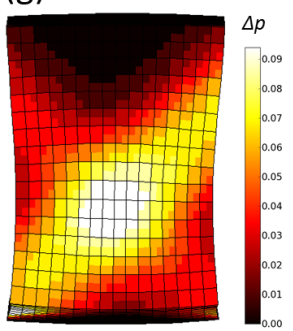

(j)

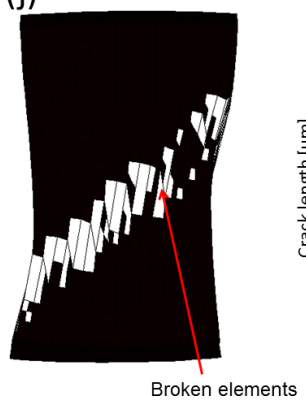

(b)

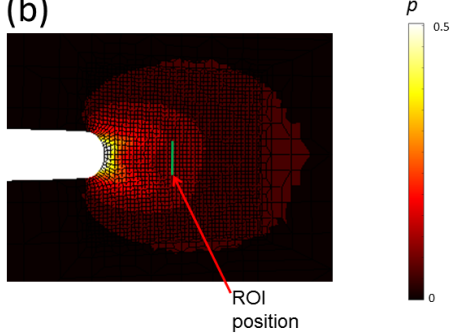

(e)

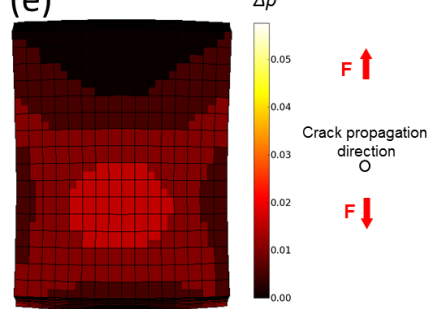

(h)

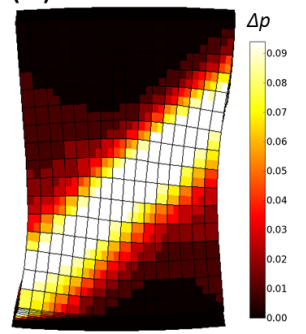

(k)

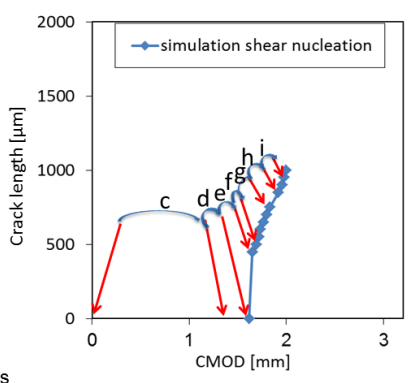

Figure 15: Results of a 3D simulation of the CT-like specimen using a Gurson-TvergaardNeedleman model combined with a shear void nucleation term. (a) Stress field in the loading direction. (b) Equivalent strain field in the plastic zone. (c)-(i) incremental strain fields in the ROI for load steps corresponding to Figure 6 $1050 \mu \mathrm{m}$ ahead from the notch root. (j) Final crack position. (k) Indication of the corresponding load step 
Figure 8). To interpret further the existence of these bands and in particular the strain distribution 2D simulations are performed to account for material heterogeneity [58]. The simulations are carried out in plane strain conditions as it has been shown that crack propagation occurs under such conditions. Isotropic hardening is described by

$$
R(p)=R_{0}\left[1+K_{0} p+K_{1}\left(1-e^{-k_{1} p}\right)+K_{2}\left(1-e^{-k_{2} p}\right)\right]
$$

where the material parameters $R_{0}, K_{0}, K_{1}, k_{1}, K_{2}, k_{2}$ are given in Table 1 . The weakening is described by multiplying the hardening law with a perturbation factor $0<x<1$

$$
R(p)=(1-x) R_{0}\left[1+K_{0} p+K_{1}\left(1-e^{-k_{1} p}\right)+K_{2}\left(1-e^{-k_{2} p}\right)\right]
$$

The mesh with the soft zone and the line along which the strain profile is analyzed are given in Figure 16(a). Loading of the upper and lower ends of

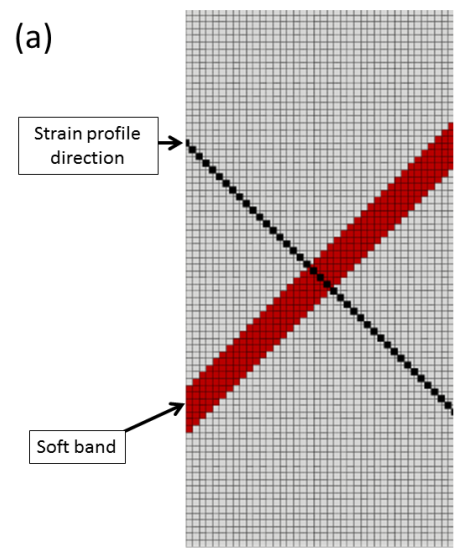

(b)

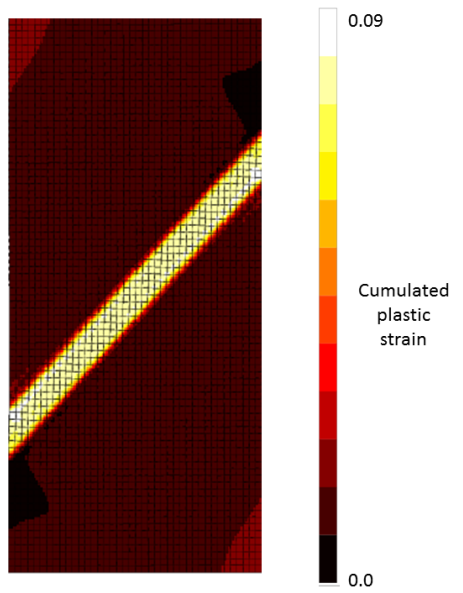

Figure 16: 2D plane strain simulation using a slant soft band. (a) 2D mesh. (b) Equivalent plastic strain field when $x=10 \%$

the meshed zone leads to a slant strain distribution for a perturbation of $10 \%$ shown in Figure 16(b).

The strain profiles normal to the meshed soft band are reported in Figure 17 The equivalent plastic strain increases in both regions (i.e., within and outside 
the band). The strain ratio is of the order of 2 for a perturbation $x=10 \%$.

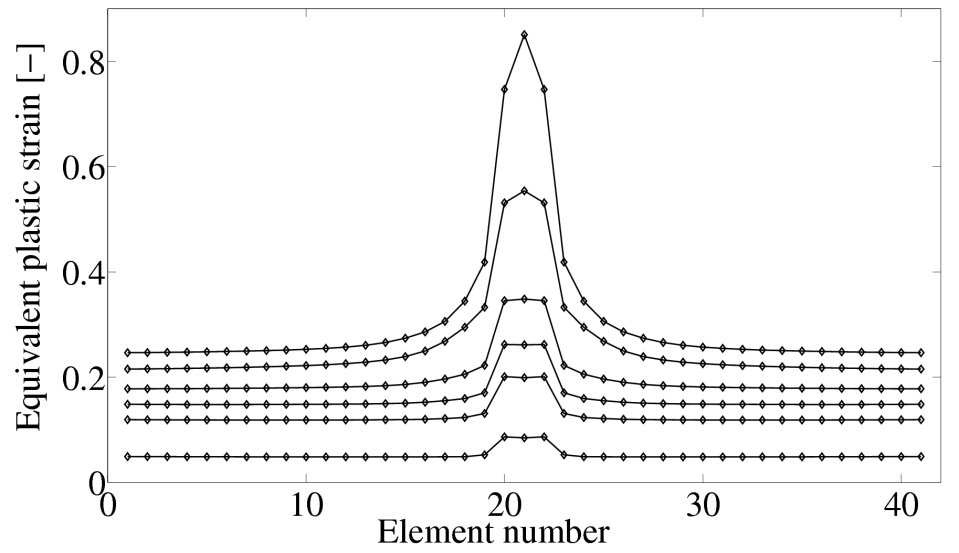

Figure 17: Equivalent strain profiles normal to the band (see Figure 16 (a)) for a 10-\% perturbation

Figure 18 shows the change of the strain ratio for different perturbation levels. The stronger the perturbation the higher the initial strain ratio and the earlier the final increase of the strain ratio. In the experimental case the strain ratio is still of the order of 2 for a strain outside the band of $\approx 0.22$. A soft perturbation of the order of $10 \%$ reproduces rather well these experimental findings.

\subsubsection{Randomly distributed soft zones}

There is no evident reason for soft zones in the material to be distributed in slant bands. Consequently soft zones with a size of $50 \mu \mathrm{m} \times 50 \mu \mathrm{m}$ are randomly distributed in an additional simulation. These dimensions are close to the mean grain size of the studied aluminum alloy. The soft zones were randomly distributed in the central part of the meshed region. The soft phase fraction has been chosen to be the same as in the previously reported calculation with a soft slant band. The soft zone distribution is depicted in Figure 19(a). The resulting equivalent strain field is shown in Figure 19(b). Some development of slant bands occurs at 0.14 average equivalent strain, which is relatively early 

tween the bands and the surrounding material is less $(i . e ., \approx 1.15)$ than for the simulation where all soft zones are located in a single slant band.

\subsection{Discussion}

Combining three dimensional in situ imaging of a flat specimen with DVC slant fracture region. These parallel slant bands have an intermittent activity. The crossing bands initially form a "waffle"-like pattern due to strain ridges and valleys. The ratio of the strain within the bands and the surrounding material is of the order of 1.5 to 2 .

540

Three-dimensional FE simulations using von Mises plasticity or a GursonTvergaard-Needleman-type model do not capture the slant bands. With a standard Gurson-Tvergaard-Needleman-model the crack remains flat. The flat-toslant crack transition can be reproduced successfully using a Lode parameterbased void nucleation term in a Gurson-Tvergaard-Needleman-model. The early slant bands are, however, not reproduced.

The strain partitioning is further investigated via plane strain simulations where a slant soft zone is modeled. A plane strain condition had been identified for the crack propagation direction in the region where the crack is slanted 44. For a perturbation of $10 \%$, strain partitioning between the band and the surrounding material, and a strain level at localization are in agreement with the experimental findings. A softening effect is thus identified rather than shear localization where all strains would localize within the band.

The question that arises is what could be at the origin of these bands. The heterogeneous strain fields could be linked to heterogeneous microstructures and resulting plasticity [58]. Local material heterogeneity caused by crystallographic texture, which is referred to as roping, could also be a possibility [59]. In that case these local textures are the result of ex-super grains that existed at some point during material processing. However, the characteristic lengths identified in Ref. 59] are substantially larger than what is found herein, namely, more 


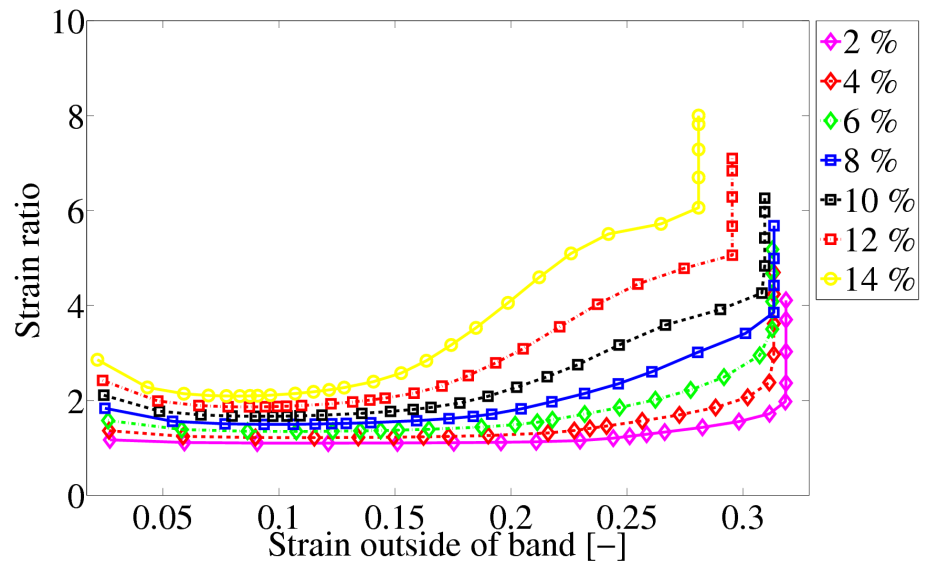

Figure 18: Strain ratio versus strain outside the band for different perturbation levels $(2 \% \leq$ $x \leq 14 \%)$

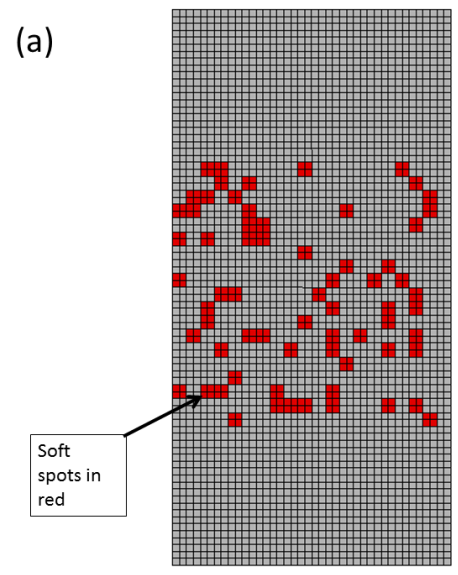

(b)

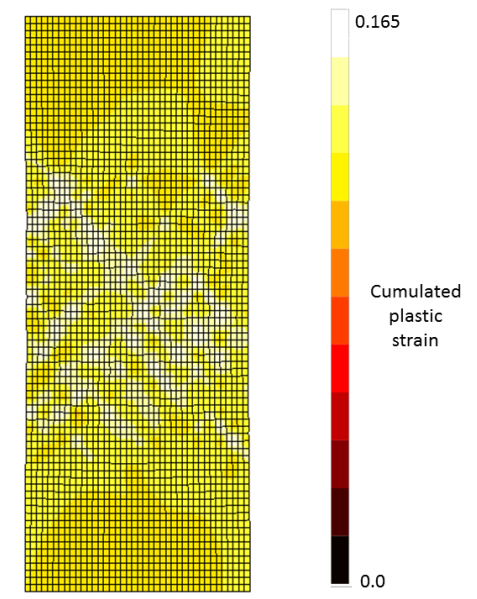

Figure 19: 2D plane strain simulation using randomly distributed soft zones. (a) 2D mesh. (b) Equivalent plastic strain field when the mean level is equal to 0.14 and $x=10 \%$ 
are found are slanted and evenly spaced. There is no obvious reason to find such slant grain arrangements in soft zones. Additionally the characteristic spacing, ordered nature and intermittent activity of the bands makes a purely material heterogeneity based origin less likely.

565 tribution, slant bands are obtained at early loading stages under plane strain conditions. These soft zones may be a possible origin of the phenomena reported herein. However, the strain ratio within and outside the bands is not similar to the experimental findings. Using different surface fractions or softness, results the intermittent activity of the bands is not captured through these effects.

In the present models no ingredients to reproduce the intermittent strained band activity are used. Origins of the intermittent nature of the strained bands could be DSA (i.e., Portevin-Le-Chatelier effect 60, 19]). This observation is bands may become inactive and damage softening does not seem to influence these processes on the first order. It is, however, surprising that the experimentally measured strained bands are stable in space with respect to microstructural features. This is generally not found for moving PLC bands on smooth specimens as in these cases the strained bands move in time and even out the strain heterogeneities in the different regions. Here, however, the notch naturally concentrates the strain fields and may prevent the bands from moving. Similar strained bands have been found on Kahn tear test sample surfaces made of AlLi alloy 18 after tearing. Deformation patterns in slant crossing bands ahead of notches have also been suggested in early works on these phenomena 61 .

Further, it is experimentally shown that inside the strained bands voids change shape and rotate to align along the direction of the band. The question arises whether the shape evolution of pre-existing voids can lead to strain localization and damage softening. It is noteworthy that this evolution takes 590 
void growth is the result of previous, and thus governing, deformation and concentration in strained bands. It is certainly of interest to investigate the effect of void shape changes in such strained bands on the fracture resistance of the material. It is likely that there will be an additional localization effect due to material bulk during ductile tearing. The region of interest is located $1080 \mu \mathrm{m}$ ahead of a notched 1-mm thick plate made of ductile aluminum alloy containing initial porosities $(\approx 0.33$ vol\% $)$ and particles $(\approx 0.45$ vol\% $)$. This analysis is made possible by the combination of in situ synchrotron laminography and dig615 of strain and microstructure maps has yielded the following results:

- Several parallel, crossing and slant strained bands are active from the very early stages of loading (i.e., max. 0.03 equivalent von Mises strain). 
- The analysis of incremental strain fields shows that the activity of the bands is intermittent over the whole loading history.

- The spatial location of these bands compared to the microstructure is stable, i.e., the strain activity is not evening out the strain fields.

- Even very concentrated (strained) bands with high von Mises equivalent strain levels (i.e., 0.10) may become inactive and other bands become active at very late stages of loading.

- The typical strained band spacing is $150-250 \mu \mathrm{m}$.

- The ratio of the equivalent strain within and outside the bands is about 1.5 to 2 .

- In the local area of observation substantial void growth could not be detected at micrometer resolution before the occurrence of strained bands.

- The fact that strained bands may switch off at the end of the test indicates that the mechanisms at play for strain concentration may differ from damage softening.

- The observed slant strained bands at early loading stages cannot be reproduced using a Gurson-Tvergaard-Needleman-type model with Lode parameter-based shear void nucleation. The flat to slant crack transition is however successfully reproduced.

- 2D plane strain simulations accounting for a soft zone yield strain ratios within the band and the surrounding material similar to the measurements for a $10-\%$ weakening. A softening effect is thus identified rather than shear localization where all strains would localize within the band. Using randomly distributed soft zones, slant strained bands can be obtained. The ratio of the strain within and outside the bands is, however, substantially lower than in the experimental findings. 
Last, investigations on other Al-alloys and specimen geometries would be useful to confirm the present results, which have also be found on a low work hardening alloy (i.e., AA2198 T8 [43]).

\section{Acknowledgements}

The financial support by Fédération Francilienne de Mécanique and Agence Nationale de la Recherche (ANR-14-CE07-0034-02 grant for COMINSIDE project) are gratefully acknowledged. Constellium C-Tec is acknowledged for material supply. The authors would also like to acknowledge ESRF for providing beamtime (experiment MA1006), Dr. M. Mavrogordato and Prof. I. Sinclair for help with the experiment. They particularly thank Prof. J.W. Hutchinson for discussing strain partitioning.

\section{References}

[1] T. Le Jolu, T. F. Morgeneyer, A. Denquin, M. Sennour, A. Laurent, J. Besson, A.-F. Gourgues-Lorenzon, Microstructural characterization of internal welding defects and their effect on the plastic behavior of FSW joints of AA2198 Al-Cu-Li alloy, Metall. Mat. Trans. A 45 (2014) 55315544 .

[2] T. Le Jolu, T. F. Morgeneyer, A. Denquin, A.-F. Gourgues-Lorenzon, Fatigue lifetime and tearing resistance of AA2198 alloy friction stir welds: Effect of defects, Int. J. Fat. 70 (2015) 463-472.

[3] J. Papasidero, V. Doquet, D. Mohr, Determination of the Effect of Stress State on the Onset of Ductile Fracture Through Tension-Torsion Experiments, Exp. Mech. 54 (2) (2014) 137-151.

[4] J. Rice, The Localization of Plastic Deformations, North-Holland, 1976, pp. 207-220. 
[5] C. Tekoğlu, J. W. Hutchinson, T. Pardoen, On localization and void coalescence as a precursor to ductile fracture, Phil. Trans. Royal Soc. London A373 (2038) (2015) 20140121.

[6] A. Needleman, V. Tvergaard, Analyses of Plastic Flow Localization in Metals, Appl. Mech. Rev. 45 (3S) (1992) S3-S18.

[7] A. Needleman, The Effect of Rate Dependence on Localization of Deformation and Failure in Softening Solids, J. Appl. Mech. 82 (2) (2015) 021002-7.

[8] N. Fleck, J. Hutchinson, A phenomelogical theory for strain gradient effects in plasticity, J. Mech. Phys. Solids 41 (12) (1993) 1825-1857.

[9] E. Mahgoub, X. Deng, M. Sutton, Three dimensional stress and deformation fields around flat and slant cracks under remote mode I loading conditions, Eng. Fract. Mech. 70 (2003) 2527-2542.

[10] J. Besson, Continuum models of ductile fracture: A review, Int. J. Damage Mech. 19 (2010) 3-52.

[11] J. Besson, D. Steglich, W. Brocks, Modeling of crack growth in round bars and plane strain specimens, Int. J. Solids Struct. 38 (46-47) (2001) 82598284.

[12] T. F. Morgeneyer, J. Besson, Flat to slant ductile fracture transition: Tomography examination and simulations using shear-controlled void nucleation, Scripta Mat. 65 (2011) 1002-1005.

[13] K. Nahshon, J. Hutchinson, Modification of the gurson model for shear failure, Eur. J. Mech. A/Solids 27 (2008) 1-17.

[14] J. Besson, C. McCowan, E. Drexler, Modeling flat to slant fracture transition using the computational cell methodology, Eng. Fract. Mech. 104 (2013) 80-95.

695

[15] T. Pardoen, F. Hachez, B. Marchioni, P. Blyth, A. Atkins, Mode I fracture of sheet metal, J. Mech. Phys. Solids 52 (2004) 423-452. 
[16] S. El-Naaman, K. Nielsen, Observations on mode I ductile tearing in sheet metals, Eur. J. Mech. A/Solids 42 (2013) 54-62.

[17] B. Simonsen, R. Tornqvist, Experimental and numerical modelling of ductile crack propagation in large-scale shell structures, Marine Struct. 17 (1) (2004) 1-27.

[18] D. Delafosse, G. Lapasset, K. LP, Dynamic strain-aging and crack propagation in the 2091 Al-Li alloy, Scripta Metall. Mat. 29 (11) (1993) 1379-1384.

[19] G. Rousselier, S. Quilici, Combining porous plasticity with Coulomb and Portevin-Le Chatelier models for ductile fracture analyses, Int. J. Plasticity 69 (2015) 118-133.

[20] T.-S. Cao, M. Maziere, K. Danas, J. Besson, A model for ductile damage prediction at low stress triaxialities incorporating void shape change and void rotation, Int. J. Solids Struct. 63 (2015) 240-263.

[21] D. Song, M. Agoras, P. P. Castaneda, The evolution of pore shape and orientation in plastically deforming metals: Implications for macroscopic response and shear localization, Mech. Mat. 90 (2015) 47-68.

[22] M. E. Torki, A. A. Benzerga, J. B. Leblond, On Void Coalescence Under Combined Tension and Shear, J. Appl. Mech. 82 (7, SI).

[23] E. Maire, P. J. Withers, Quantitative X-ray tomography, Int. Mat. Rev. 59 (1) (2014) 1-43.

[24] T. Morgeneyer, H. Proudhon, P. Cloetens, W. Ludwig, Q. Roirand, L. Laiarinandrasana, E. Maire, Nanovoid morphology and distribution in deformed HDPE studied by magnified synchrotron radiation holotomography, Polymer 55 (2014) 6439-6443.

[25] E. Nizery, H. Proudhon, J. Buffiere, P. Cloetens, T. F. Morgeneyer, S. Forest, Three dimensional characterization of intermetallic particles in highstrength aluminium alloys using synchrotron X-ray tomography, Phil. Mag. 95 (25) (2015) 2731-2746. 
[26] L. Laiarinandrasana, T. F. Morgeneyer, H. Proudhon, F. N'guyen, E. Maire, Effect of multiaxial stress state on morphology and spatial distribution of voids in deformed semi-crystalline polymer assessed by X-ray tomography, Macromolecules 45 (2012) 4658-4668.

[27] L. Helfen, T. Baumbach, P. Mikulík, D. Kiel, P. Pernot, P. Cloetens, J. Baruchel, High-resolution three-dimensional imaging of flat objects by synchrotron-radiation computed laminography, Appl. Phys. Lett. 86 (7) (2005) 071915.

[28] L. Helfen, A. Myagotin, P. Mikulík, P. Pernot, A. Voropaev, M. Elyyan, M. Di Michiel, J. Baruchel, T. Baumbach, On the implementation of computed laminography using synchrotron radiation, Rev. Sci. Instrum. $82(063702)$.

[29] Y. Shen, T. F. Morgeneyer, J. Garnier, L. Allais, L. Helfen, J. Crepin, Three-dimensional quantitative in-situ study of crack initiation and propagation in AA6061 Al-alloy sheets via synchrotron laminography and finiteelement simulations, Acta Mat. 61 (2013) 2571-2582.

[30] T. F. Morgeneyer, L. Helfen, I. Sinclair, H. Proudhon, F. Xu, T. Baumbach, Ductile crack initiation and propagation assessed via in situ synchrotron radiation computed laminography, Scripta Mat. 65 (2011) 1010-1013.

[31] H. Toda, I. Sinclair, J. Buffière, E. Maire, T. Connolley, M. Joyce, K. H. Khor, P. Gregson, Assessment of the fatigue crack closure phenomenon in damage-tolerant aluminium alloy by in-situ high-resolution synchrotron X-ray microtomography, Phil. Mag. 83 (21) (2003) 2429-2448.

[32] H. Toda, I. Sinclair, J. Buffière, E. Maire, K. Khor, P. Gregson, T. Kobayashi, A 3D measurement procedure for internal local crack driving forces via synchrotron X-ray microtomography, Acta Mat. 52 (2004) $1305-1317$. 
[33] M. Kobayashi, H. Toda, Y. Kawai, T. Ohgaki, K. Uesugi, D. Wilkinson, T. Kobayashi, Y. Aoki, M. Nakazawa, High-density three-dimensional mapping of internal strain by tracking microstructural features, Acta Mat. 56 (2008) 2167-2181.

[34] B. Bay, T. Smith, D. Fyhrie, M. Saad, Digital volume correlation: threedimensional strain mapping using X-ray tomography, Exp. Mech. 39 (1999) $217-226$.

[35] M. Bornert, J. Chaix, P. Doumalin, J. Dupré, T. Fournel, D. Jeulin, E. Maire, M. Moreaud, H. Moulinec, Mesure tridimensionnelle de champs cinématiques par imagerie volumique pour l'analyse des matériaux et des structures, Inst. Mes. Métrol. 4 (2004) 43-88.

[36] E. Verhulp, B. van Rietbergen, R. Huiskes, A three-dimensional digital image correlation technique for strain measurements in microstructures, J. Biomech. 37 (9) (2004) 1313-1320.

[37] S. Roux, F. Hild, P. Viot, D. Bernard, Three dimensional image correlation from X-Ray computed tomography of solid foam, Comp. Part A 39 (8) (2008) 1253-1265.

[38] F. Hild, E. Maire, S. Roux, J. Witz, Three dimensional analysis of a compression test on stone wool, Acta Mat. 57 (2009) 3310-3320.

[39] J. Réthoré, N. Limodin, J. Buffière, F. Hild, W. Ludwig, S. Roux, Digital volume correlation analyses of synchrotron tomographic images, J. Strain Analysis 46 (2011) 683-695.

[40] S. Nielsen, H. Poulsen, F. Beckmann, C. Thorning, J. Wert, Measurements of plastic displacement gradient components in three dimensions using marker particles and synchrotron X-ray absorption microtomography, Acta Mat. 51 (8) (2003) 2407-2415. 
[41] K. Haldrup, S. Nielsen, J. Wert, A General Methodology for Full-Field Plastic Strain Measurements Using X-ray Absorption Tomography and Internal Markers, Exp. Mech. 48 (2008) 199-211.

[42] T. F. Morgeneyer, L. Helfen, H. Mubarak, F. Hild, 3D digital volume correlation of synchrotron radiation laminography images of ductile crack initiation: An initial feasibility study, Exp. Mech. 53 (2013) 543-556.

[43] T. F. Morgeneyer, T. Taillandier-Thomas, L. Helfen, T. Baumbach, I. Sinclair, S. Roux, F. Hild, In situ 3D observation of early strain localisation during failure of thin Al alloy (2198) sheet, Acta Mat. 69 (2014) 78-91.

[44] A. Buljac, T. Taillandier-Thomas, T. F. Morgeneyer, L. Helfen, S. Roux, F. Hild, Slant strained band development during flat to slant crack transition in AA 2198 T8 sheet: in situ 3D measurements, Int. J. Fract. (DOI: 10.1007/s10704-015-0052-z).

[45] T. F. Morgeneyer, M. Starink, I. Sinclair, Evolution of voids during ductile crack propagation in an Al-alloy sheet toughness test studied by microcomputed tomography, Acta Mat. 56 (2008) 1671-1679.

[46] T. F. Morgeneyer, J. Besson, H. Proudhon, M. Starink, I. Sinclair, Experimental and numerical analysis of toughness anisotropy in AA2139 Al-alloy sheet, Acta Mat. 57 (2009) 3902-3915.

[47] T. Weitkamp, P. Tafforeau, E. Boller, P. Cloetens, J. P. Valade, P. Bernard, F. Peyrin, W. Ludwig, L. Helfen, J. Baruchel, Parallel-beam imaging at the ESRF beamline ID19: current status and plans for the future, Vol. 1234 of Proceedings SRI 2009, AIP Conference Proceedings, 2010, pp. 83-86.

[48] A. Myagotin, A. Voropaev, L. Helfen, D. Hanschke, T. Baumbach, Efficient volume reconstruction for parallel-beam computed laminography by filtered backprojection on multi-core clusters., IEEE Transactions on Image Processing 22 (12) (2013) 5348-5361. 
[49] P.-A. Douissard, A. Cecilia, X. Rochet, X. Chapel, T. Martin, T. van de Kamp, L. Helfen, T. Baumbach, L. Luquot, X. Xiao, J. Meinhardt, A. Rack, A versatile indirect detector design for hard X-ray microimaging, J. Instrum. 7 (2012) P09016.

[50] T. Ueda, L. Helfen, T. F. Morgeneyer, In-situ laminography study of three-

[56] H. Leclerc, J. Périé, F. Hild, S. Roux, Digital volume correlation: What are the limits to the spatial resolution?, Mech. \& Indust. 13 (2012) 361-371.

[57] H. Toda, H. Oogo, K. Uesugi, M. Kobayashi, Roles of Pre-Existing Hydrogen Micropores on Ductile Fracture, Mat. Trans. 50 (9) (2009) 2285-2290.

830 dimensional individual void shape evolution at crack initiation and comparison with GTN-type simulations, Acta Mat. 78C (2014) 254-270.

[51] T. Smith, B. Bay, M. Rashid, Digital volume correlation including rotational degrees of freedom during minimization, Exp. Mech. 42 (3) (2002) $272-278$.

[52] H. Leclerc, J. Périé, S. Roux, F. Hild, Voxel-scale digital volume correlation, Exp. Mech. 51 (4) (2011) 479-490.

[53] T. Taillandier-Thomas, S. Roux, T. F. Morgeneyer, F. Hild, Localized strain field measurement on laminography data with mechanical regularization, Nucl. Instr. Meth. Phys. Res. Sect. B 324 (2014) 70-79.

[54] A. Bouterf, S. Roux, F. Hild, J. Adrien, E. Maire, Digital volume correlation applied to X-ray tomography images from spherical indentation tests on lightweight gypsum, Strain 50 (5) (2014) 444-453.

[55] F. Hild, A. Bouterf, L. Chamoin, F. Mathieu, J. Neggers, F. Pled, Z. Tomičević, S. Roux, Toward 4d mechanical correlation, Adv. Mech. Simul. Eng. Sci. 3 (DOI:10.1186/s40323-016-0070-z) (2016) 1-26.

[58] J. Hutchinson, V. Tvergaard, Shear band formation in plane-strain, Int. J. Solids Struct. 17 (5) (1981) 451-470. 
[59] L. Qin, M. Seefeldt, P. V. Houtte, Analysis of roping of aluminum sheet materials based on the meso-scale moving window approach, Acta Mat. 84 (2015) 215-228.

[60] H. Wang, C. Berdin, M. Maziere, S. Forest, C. Prioul, A. Parrot, P. LeDelliou, Portevin-Le Chatelier (PLC) instabilities and slant fracture in CMn steel round tensile specimens, Scripta Mat. 64 (5) (2011) 430-433.

[61] G. Hahn, A. Rosenfield, Local yielding and extension of a crack under plane stress, Acta Metall. 13 (3) (1965) 293-306. 